\title{
Ground Truth Measurements Plan for the Multispectral Thermal Imager (MTI) Satellite
}

by

A. J. Garrett

Westinghouse Savannah River Company

Savannah River Site

Aiken, South Carolina 29808

R. J. Kurzeja

B. L. Osteen

M. M. Pendergast

E. Villa-Aleman

M. J. Parker

DOE Contract No. DE-AC09-96SR18500

This paper was prepared in connection with work done under the above contract number with the U. S.

Department of Energy. By acceptance of this paper, the publisher and/or recipient acknowledges the U.S. Government's right to retain a nonexclusive, royalty-free license in and to any copyright covering this paper, along with the right to reproduce and to authorize others to reproduce all or part of the copyrighted paper. 


\section{DISCLAIMER}

This report was prepared as an account of work sponsored by an agency of the United States Government. Neither the United States Government nor any agency thereof, nor any of their employees, makes any warranty, express or implied, or assumes any legal liability or responsibility for the accuracy, completeness, or usefulness of any information, apparatus, product or process disclosed, or represents that its use would not infringe privately owned rights. Reference herein to any specific commercial product, process or service by trade name, trademark, manufacturer, or otherwise does not necessarily constitute or imply its endorsement, recommendation, or favoring by the United States Government or any agency thereof. The views and opinions of authors expressed herein do not necessarily state or reflect those of the United States Government or any agency thereof.

This report has been reproduced directly from the best available copy.

Available for sale to the public, in paper, from: U.S. Department of Commerce, National Technical Information Service, 5285 Port Royal Road, Springfield, VA 22161, phone: (800) 553-6847,

fax: (703) 605-6900

email: orders@ntis.fedworld.gov

online ordering: http://www.ntis.gov/ordering.htm

Available electronically at http://www.doe.gov/bridge

Available for a processing fee to U.S. Department of Energy and its contractors, in paper, from:

U.S. Department of Energy, Office of Scientific and Technical Information, P.O. Box 62,

Oak Ridge, TN 37831-0062,

phone: (865)576-8401,

fax: (865)576-5728

email: reportseadonis.osti.gov 


\section{DISCLAIMER}

Portions of this document may be illegible in electronic image products. Images are produced from the best available original document. 


\title{
Ground Truth Measurements Plan for the Multispectral Thermal Imager (MTI) Satellite (U)
}

\author{
Alfred J. Garrett, Robert.J. Kurzeja, B. Lance O'Steen, Matthew J. Parkèr, \\ Malcolm M. Pendergast, Eliel Villa-Aleman
}

Savannah River Technology Center, Aiken, SC 29808

\begin{abstract}
Sandia National Laboratories (SNL), Los Alamos National Laboratory (LANL) and the Savannah River Technology Center (SRTC) have developed a diverse group of algorithms for processing and analyzing the data that will be collected by the Multispectral Thermal Imager (MTI) after launch late in 1999. Each of these

- algorithms must be verified by comparison to independent surface and atmospheric measurements. SRTC has selected 13 sites in the continental U.S. for ground truth data collections. These sites include a high altitude cold water target (Crater Lake), cooling lakes and towers in the warm, humid southeastern US, Department of Energy (DOE) climate research sites, the NASA Stennis satellite Validation and Verification (V\&V) target array, waste sites at the Savannah River Site, mining sites in the Four Corners area and dry lake beds in the southwestern US. SRTC has established mutually beneficial relationships with the organizations that manage these sites to make use of their operating and research data and to install additional instrumentation needed for MTI algorithm V\&V.
\end{abstract}

Keywords: Validation, Verification, Ground Truth, Multispectral Imaging 


\section{Ground Truth Measurements Plan for the Multi-spectral Thermal Imager (MTI) Satellite}

\section{INTRODUCTION}

The DOE Multispectral Thermal Imager (MTI) satellite will produce large amounts of high resolution imagery over 15 wavebands covering the visible, near-infrared (NIR), short-wave infrared (SWIR), mid-wave infrared (MWIR) and long-wave infrared (LWIR). The imagery will be used to demonstrate enhanced capabilities in a variety of applications, including temperature retrieval, analysis of thermal and particulate pollutant transport in surface water systems and the atmosphere, waste and mining site monitoring, vegetation health and material identification. Verification of MTI's performance in these different applications requires independent radiometric measurements and the collection of necessary collateral data, such as atmospheric temperature and humidity profiles, direct water temperature measurements and target material samples for laboratory spectral analyses. The Savannah River Technology Center (SRTC) is the DOE laboratory that is responsible for ground truth data collections. In the following sections we describe the MTI science algorithms to be verified, the ground truth collection sites and instruments and methods to be used to perform the collections.

\section{MTI SCIENCE ALGORITHMS}

\subsection{Summary of algorithms and site selection}

Smith et al. ${ }^{4}$ described 16 science algorithms for which ground truth data must be collected. In many cases, one target will provide data that can be used to validate more than one of these algorithms. In order to minimize the number of sites required to fully validate the 16 algorithms, SRTC determined what data is - required for validation of all 16 algorithms and derived a set of generic site characteristics that would be adequate to produce those data. Using the set of site characteristics as a guide, SRTC then developed a list of potential sites, performed an initial screening and then did a more detailed investigation of the remaining sites, including contacts with site management and visits. The 16 science algorithms and corresponding generic ground truth sites are listed below.

\section{Algorithm}

1. Calibration Correction

2. Interband Registration

3. Image reconstruction and Restoration

4. Physics-based Water and Land Temperature Retrieval

5. Robust Water Temperature Retrieval

6. Detection of Boundaries of Bodies of Water

7. Subpixel Temperature Retrieval

8. Industrial Heat Dissipation in Surface Water Systems

9. Industrial Heat Dissipation in the Atmosphere

10. Cloud Masks

11. Thin Cirrus Detection/Removal

12. Scattering and Absorption by Aerosols

13. Columnar Water Vapor Retrieval

14. Vegetation Health

15. Water Quality and Bathymetry

16. Material Identification

\section{Generic Ground Truth Sites}

desert dry lake beds (playas) bridges, cooling canals, satellite target array bridges, cooling canals, airstrips heated/unheated lakes, satellite target array heated/unheated lakes natural and manmade lakes and canals thermal discharge to cooling lake cooling lakes, rivers, bays cooling towers

DOE ARM sites, large lakes

DOE ARM sites

DOE ARM sites

DOE ARM sites

industrial sites

lakes in a variety of geographic locations industrial sites, uranium mines 
SRTC has selected fourteen ground truth sites across the continental US and in the western Pacific that fulfill the generic site requirements (Figure 1).

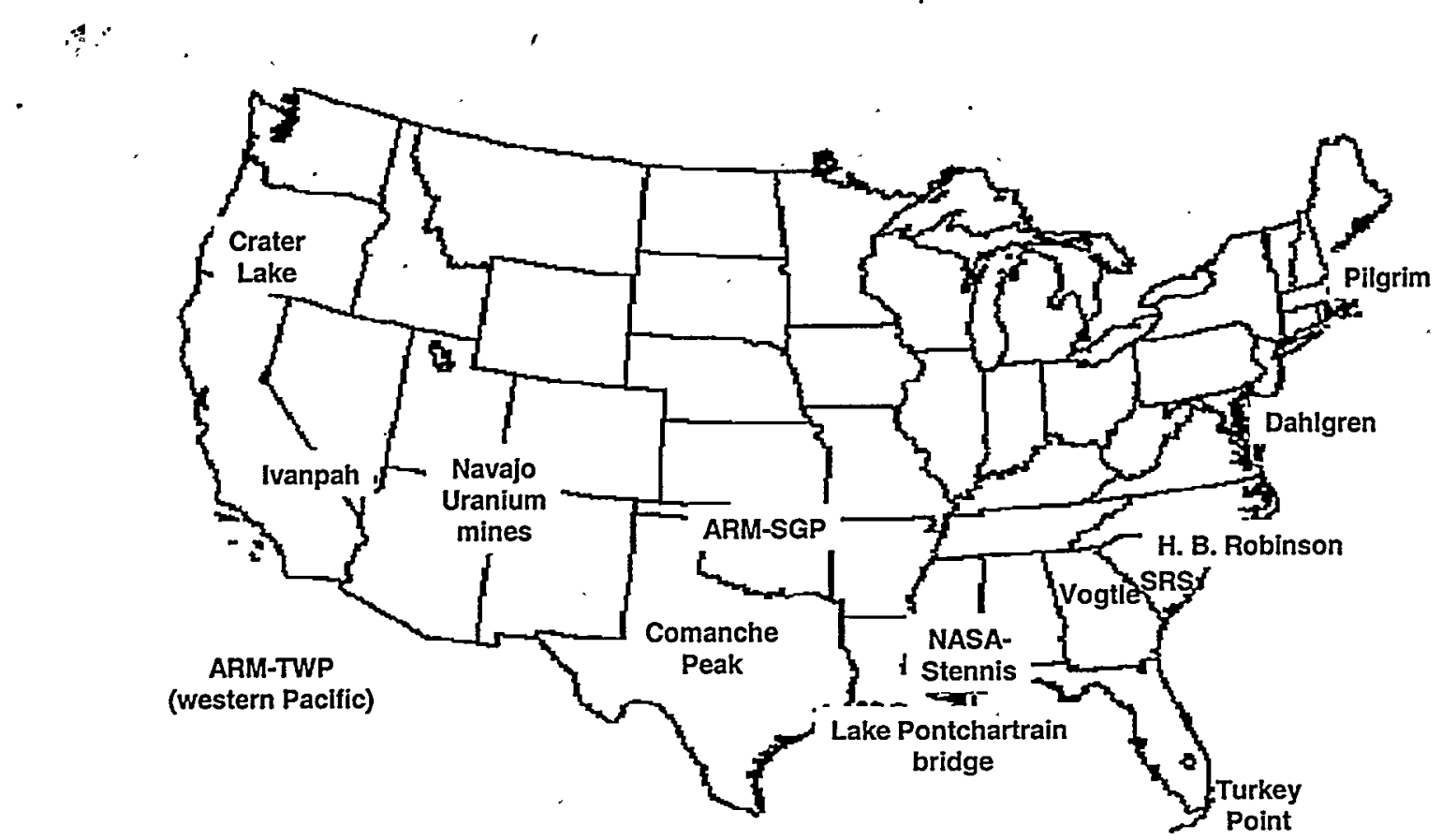

Figure 1: Locations of MTI ground truth sites.

A diverse set of organizations owns and/or manages these 14 sites. Five of the sites are nuclear power plants (Comanche Peak, Vogtle, Turkey Point, Pilgrim and H. B. Robinson) which are owned by five different utilities. The Southern Great Plains (SGP) Atmospherice Radiation Measurements (ARM) site is operated by DOE's Brookhaven National Laboratory. The Tropical Western Pacific (TWP) ARM site is on the island of Nauru, which is near the equator in the western Pacific and is operated by Los Alamos National Laboratory (LANL). Nauru is an independent political entity. The Savannah River Site (SRS) is a DOE nuclear complex largely focused on environmental restoration and storage of nuclear materials and waste. Dahlgren is a US Navy Base. Stennis is a NASA site that combines research facilities relating to remote sensing with satellite calibration and rocket engine test facilities. The Lake Pontchartrain bridges are public (roads) and private (railroads) property. The National Park Service manages Crater Lake National Park. Ivanpah playa is on government property managed by the Bureau of Land Management. The Navajo uranium mine sites are managed by the Navajo Abandoned Mine Lands (AML) Reclamation Department, which is part of the Navajo Nation's Division of Natural Resources. SRTC has developed relationships with the managers of these 14 sites. In many cases, the MTI Project is critically dependent on these site managers for support, including ground truth data, operational data and logistical support for short-term and long-term data collections. Most of the site managers want to receive MTI imagery to help them improve various aspects of their operations. All 14 site managers can terminate their relationships with SRTC (and DOE) at any time, because the working relationships are informal and not legally binding.

Key information about those sites is given below. The site information will be followed by an algorithm-by algorithm discussion that will describe the ground truth data to be taken at each of the sites. 
Table 1: Ground Truth Site Summary

\begin{tabular}{|c|c|c|c|c|}
\hline SITE & Latitude, longitude & elevation & Site contacts & Primary data \\
\hline Ivanpah playa, $\mathrm{CA}$ & $\begin{array}{l}35^{\circ} 33^{\prime} \mathrm{N} \\
115^{\circ} 23^{\prime} 7^{\prime \prime} \mathrm{W}\end{array}$ & $800 \mathrm{~m}$ & $\begin{array}{l}\text { Kurtis Thome } \\
520-621-4535 \\
\text { kurt.thome@opt-sci.arizona.edu }\end{array}$ & $\begin{array}{l}\text { Reflected solar } \\
\text { radiation ( } 0.4 \text { to } \\
2.5 \text { microns) }\end{array}$ \\
\hline $\begin{array}{l}\text { Savannah River } \\
\text { Site, SC }\end{array}$ & $\begin{array}{l}33^{\circ} 10^{\prime} \mathrm{N} \\
81^{\circ} 38^{\prime} \mathrm{W}\end{array}$ & $60 \mathrm{~m}$ & $\begin{array}{l}\text { Alfred Garrett } \\
802-725-4870 \\
\text { alfred.garrett@srs.gov }\end{array}$ & $\begin{array}{l}\text { Lake temps, } \\
\text { vegetation } \\
\text { reflectance } \\
\text { spectra }\end{array}$ \\
\hline $\begin{array}{l}\text { NASA Stennis } \\
\text { Space Center, MS }\end{array}$ & $\begin{array}{l}30^{\circ} 23^{\prime} 15^{\prime \prime} \mathrm{N} \\
89^{\circ} 37^{\prime} 38^{\prime \prime} \mathrm{W}\end{array}$ & $10 \mathrm{~m}$ & $\begin{array}{l}\text { Mary Pagnutti (Lock-Mart) } \\
\text { 228-688-2135 } \\
\text { mpagnutt@ssc.nasa.gov }\end{array}$ & $\begin{array}{l}\text { lake } \\
\text { temperatures, } \\
\text { V\&V target array } \\
\text { reflectances } \\
\end{array}$ \\
\hline $\begin{array}{l}\text { Vogtle Nuclear } \\
\text { Power Plant, GA }\end{array}$ & $\begin{array}{l}33^{\circ} 08^{\prime} 30^{\prime \prime} \mathrm{N} \\
81^{\circ} 45^{\prime} 44^{\prime \prime} \mathrm{W}\end{array}$ & $50 \mathrm{~m}$ & $\begin{array}{l}\text { Clay Chastain } \\
706-826-3160 \text {, ext. } 181\end{array}$ & $\begin{array}{l}\text { Cooling tower IR } \\
\text { and visible } \\
\text { images }\end{array}$ \\
\hline $\begin{array}{l}\text { H. B. Robinson } \\
\text { Nuclear Power } \\
\text { Plant, SC }\end{array}$ & $\begin{array}{l}34^{\circ} 24^{\prime} 02^{\prime \prime} \mathrm{N} \\
80^{\circ} 09^{\prime} 05^{\prime \prime} \mathrm{W}\end{array}$ & $50 \mathrm{~m}$ & $\begin{array}{l}\text { Darryl Gardner } \\
\text { 843-857-1144 } \\
\text { darryl.gardner@cplc.com }\end{array}$ & $\begin{array}{l}\text { Lake } \\
\text { temperatures, } \\
\text { plant operating } \\
\text { data } \\
\end{array}$ \\
\hline $\begin{array}{l}\text { Pilgrim Nuclear } \\
\text { Power Plant, MA }\end{array}$ & $\begin{array}{l}41^{\circ} 56^{\prime} 41^{\prime \prime} \mathrm{N} \\
70^{\circ} 34^{\prime} 44^{\prime \prime} \mathrm{W}\end{array}$ & Sea level & $\begin{array}{l}\text { Ken Sejkora } \\
508-830-8469 \\
\text { ksejkor@entergy.com }\end{array}$ & $\begin{array}{l}\text { Thermal plume } \\
\text { temperatures, } \\
\text { plant operating } \\
\text { data }\end{array}$ \\
\hline $\begin{array}{l}\text { Turkey Point } \\
\text { Nuclear Power } \\
\text { Plant, FL }\end{array}$ & $\begin{array}{l}25^{\circ} 26^{\prime} 04^{\prime \prime} \mathrm{N} \\
80^{\circ} 19^{\prime} 52^{\prime \prime} \mathrm{W}\end{array}$ & Sea level & $\begin{array}{l}\text { Ralph Heistand } \\
\text { 305-246-6166 } \\
\text { ralph_heistand@FPL.com }\end{array}$ & $\begin{array}{l}\text { Cooling canal } \\
\text { temperatures, } \\
\text { plant operating } \\
\text { data }\end{array}$ \\
\hline $\begin{array}{l}\text { Comanche Peak } \\
\text { Nuclear Power } \\
\text { Plant, TX }\end{array}$ & $\begin{array}{l}32^{\circ} 17^{\prime} 52^{\prime \prime} \mathrm{N} \\
97^{\circ} 47^{\prime} 06^{\prime \prime} \mathrm{W}\end{array}$ & $200 \mathrm{~m}$ & $\begin{array}{l}\text { Don Doan } \\
\text { 254-897-5345 } \\
\text { ddoan1@tuelectric.com }\end{array}$ & $\begin{array}{l}\text { Lake } \\
\text { temperatures, } \\
\text { plant operating } \\
\text { data } \\
\end{array}$ \\
\hline $\begin{array}{l}\text { Southern Great } \\
\text { Plains ARM Site, } \\
\text { OK }\end{array}$ & $\begin{array}{l}36^{\circ} 37^{\prime} \mathrm{N} \\
97^{\circ} 30^{\prime} \mathrm{W}\end{array}$ & $400 \mathrm{~m}$ & $\begin{array}{l}\text { Jim Teske } \\
\text { 580-388-4053 } \\
\text { teske@ops.sgp.arm.gov }\end{array}$ & $\begin{array}{l}\text { Crop reflectances, } \\
\text { atmospheric } \\
\text { characterization }\end{array}$ \\
\hline $\begin{array}{l}\text { Tropical Western } \\
\text { Pacific ARM Site, } \\
\text { Nauru }\end{array}$ & $\begin{array}{l}31^{\prime} 16^{\prime \prime} \mathrm{S} \\
166^{\circ} 55^{\prime} 36^{\prime \prime} \mathrm{E}\end{array}$ & Sea level & $\begin{array}{l}\text { Bill Clements } \\
\text { 505-667-1186 } \\
\text { clements@lanl.gov }\end{array}$ & $\begin{array}{l}\text { Ocean } \\
\text { temperature, } \\
\text { atmospheric data } \\
\text { Water } \\
\text { temperatures } \\
\end{array}$ \\
\hline $\begin{array}{l}\text { Dahlgren Naval } \\
\text { Base, VA }\end{array}$ & $\begin{array}{l}38^{\circ} 30^{\prime} 9.6^{\prime \prime} \mathrm{N} \\
77^{\circ} 02^{\prime} 30.8^{\prime \prime} \mathrm{W}\end{array}$ & Sea level & $\begin{array}{l}\text { Amy Brumfield } \\
540-653-3894 \\
\text { abrumfie@jwac.com }\end{array}$ & $\begin{array}{l}\text { Runway surface } \\
\text { temperatures, } \\
\text { roof reflectances }\end{array}$ \\
\hline $\begin{array}{l}\text { Crater Lake } \\
\text { National Park, OR }\end{array}$ & $\begin{array}{l}42^{\circ} 56^{\prime} \mathrm{N} \\
122^{\circ} 7^{\prime} \mathrm{W}\end{array}$ & $2100 \mathrm{~m}$ & $\begin{array}{l}\text { Mark Buktenica } \\
541-594-2211 \\
\text { mark_buktenica@nps.gov }\end{array}$ & $\begin{array}{l}\text { Lake } \\
\text { temperatures, } \\
\text { turbidity, local } \\
\text { weather data } \\
\end{array}$ \\
\hline $\begin{array}{l}\text { Navajo Uranium } \\
\text { Mine Sites, } A Z\end{array}$ & $\begin{array}{l}35^{\circ} 39^{\prime} 7^{\prime \prime} \mathrm{N} \\
111^{\circ} 16^{\prime} 41^{\prime \prime} \mathrm{W}\end{array}$ & $1300 \mathrm{~m}$ & $\begin{array}{l}\text { Ray Russell } \\
\text { 520-871-6359 } \\
\text { aml_russell@dine.navajo.org }\end{array}$ & $\begin{array}{l}\text { Mine tailings and } \\
\text { undisturbed soil } \\
\text { characterization }\end{array}$ \\
\hline $\begin{array}{l}\text { Lake Pontchartrain } \\
\text { railroad bridge, LA }\end{array}$ & $\begin{array}{l}30^{\circ} 13^{\prime} 4^{\prime \prime} \mathrm{N}, \\
89^{\circ} 49^{\prime} 29^{\prime \prime} \mathrm{W}\end{array}$ & Sea level & none & $\begin{array}{l}\text { Accurate } \\
\text { geolocation }\end{array}$ \\
\hline
\end{tabular}




\subsection{Description of Algorithms and Ground Truth Sites}

\section{Calibration Correction}

MTI has been extensively calibrated at Los Alamos using well-known source radiances traceable to standards at the National Institute of Standards and Technology (NIST). After launch, maintenance of the laboratory calibration will rely on on-board calibration sources consisting of two blackbodies, two lamps, and a reflector on a calibration wheel near the focal plane. Full-aperture calibrations will use the aperture door assembly, which is both a temperature-controlled blackbody and a diffuser for solar calibrations (Clodius et al. ${ }^{5}$ ). Also after launch, we will perform vicarious calibrations using some combination of measurements of ground surface and atmospheric properties by ground-based devices and measurements from an aircraft. We will use the methods described by Slater et $\mathrm{al}^{6}{ }^{6}$ which require that the surface being imaged be as large and uniform as possible. We will use the sun, moon and selected stars for additional vicarious calibrations.

SRTC plans to take ground-based measurements at one of the desert playas in Nevada or California. Both of these sites have been used extensively to check satellite calibrations because they are very flat and show little spatial variation in spectral properties over distances that are large relative to MTI's resolution ( $5 \mathrm{~m}$ in visible wavebands, $20 \mathrm{~m}$ in infrared). SRTC will measure radiances in the reflective wavebands ( 0.4 to $2.5 \mu$ ) with an ASD field spectrometer. An automated balloon-borne instrument package will take concurrent atmospheric profiles of humidity and temperature. SRTC will use a Sun photometer to measure aerosol content along MTI's imaging path. SRTC will also probably use visibility and particle measurement sensors.

\section{Interband Registration}

Pixels from each of MTI's 15 wavebands must be registered to the same frame of reference so that an object's location in a scene is the same in all of the images. Interband registration is crucial to most MTI applications, including material identification, water temperature, columnar water vapor and vegetation health. Scenes with long straight objects that are accurately geo-located are best suited to testing of interband registration algorithms. Examples include bridges, channels and landing strips.

SRTC has selected the following objects as candidate line sources for interband registration testing: 1) bridges and railroads (Figure 2) over Lake Pontchartrain just north of New Orleans, and 2) the airstrip at Dahlgren Naval Base in Virginia (Figure 3). SRTC plans to accurately geolocate both of these candidate line sources and characterize their spectral properties.

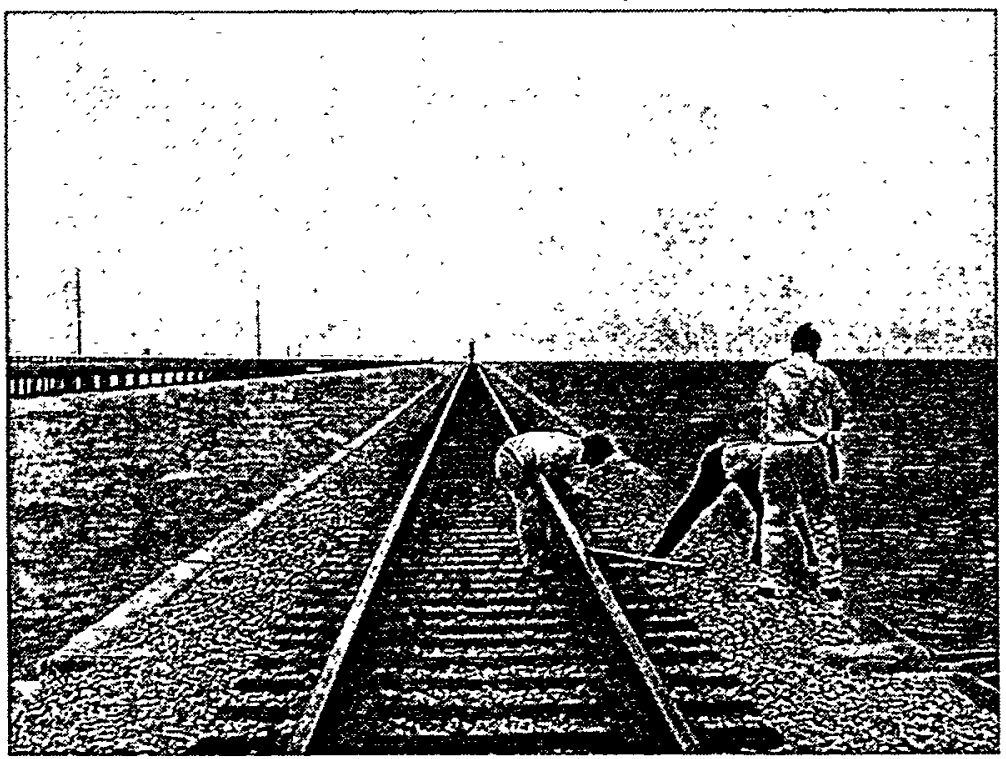

Figure 2: Railroad extending over Lake Pontchartrain, Louisiana 


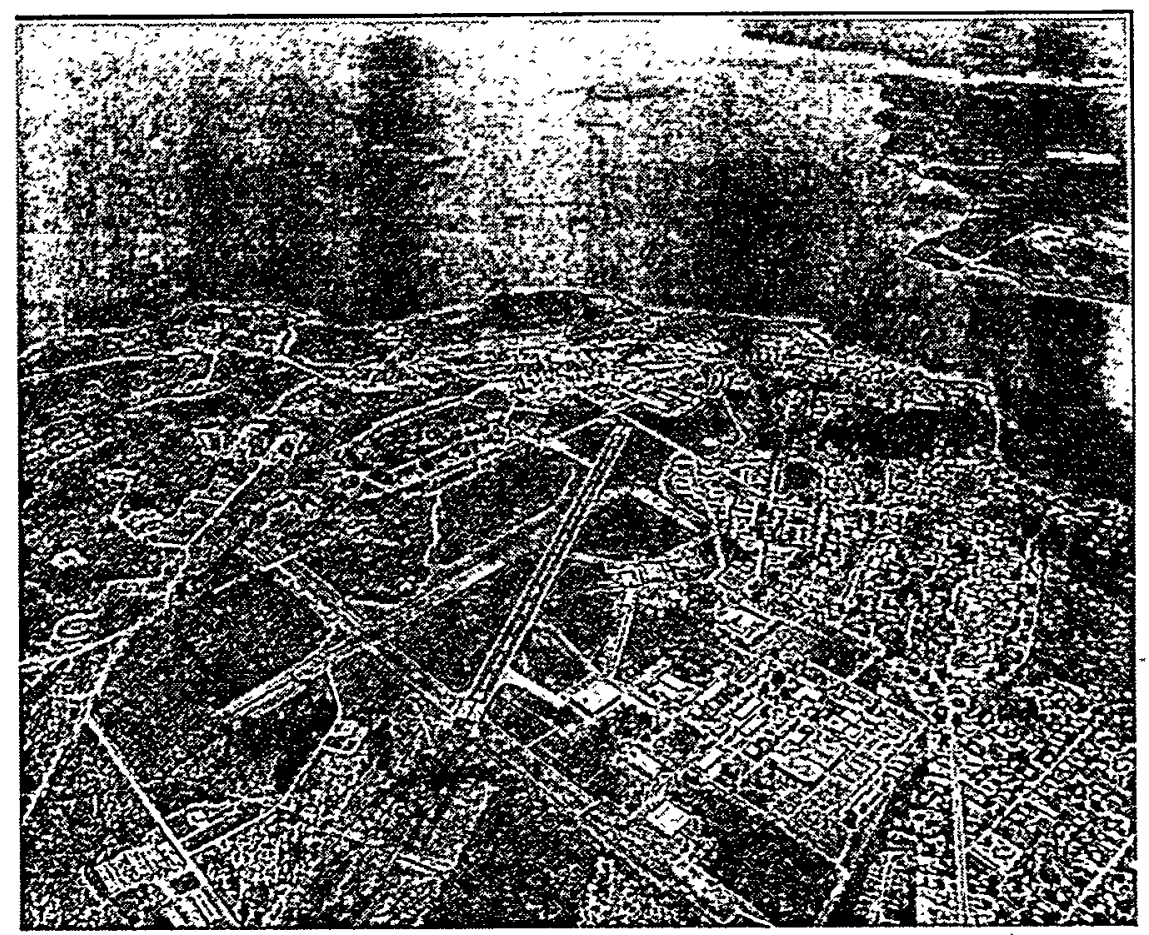

Figure 3: Dahlgren Naval Base, Virginia

\section{Image Restoration and Reconstruction}

Image restoration algorithms attempt to correct the measured image for degradation caused by sources of blurring and noise. Blurring can be caused by atmospheric turbulence, scattering of light from adjacent surface elements and aerosols, telescope point spread function, motion and jitter during image acquisition and satellite electronics. Sources of noise include thermal noise, correlated noise (streaking) and quantization noise.

The same objects that will used for testing of interband registration algorithms will also be suitable for testing of image restoration and reconstruction algorithms. In addition, uniform surfaces such as lakes with weak temperature gradients on calm days can be used to quantify the amount of correlated noise.

\section{Physics-based Water and Land Temperature Retrieval}

MTI's physics-based temperature retrieval algorithm uses MODTRAN to iterate columnar water vapor and atmospheric temperatures over a small range until the retrieved surface temperature is the same for all spectral channels and at the same time the measured radiances are matched. For land surfaces during the day, the NIR and SWIR channels will be used to identify the surface material, emissivities will be taken from standard sources and the iteration will be performed based on those emissivities.

SRTC will provide highly accurate water temperatures from unheated lakes at the Savannah River Site and from the H. B. Robinson cooling lake to test the temperature retrieval algorithm (Figure 4). The data provided by SRTC will include radiometer measurements of the true surface (skin) temperature, which can be directly. 
compared to temperatures measured by the satellite, and the bulk water temperature, which is often the only temperature measured by in situ devices. Remote sensing systems measure the temperature of a very thin layer or "skin" of water which is less than one millimeter thick and which usually is colder than the bulk water temperature just below. The skin temperature is often lower than the bulk water temperature because it strikes a balance between evaporative energy losses to the atmosphere above and the upward transport of heat from the bulk water layer below. SRTC will also provide atmospheric profile data from those sites.

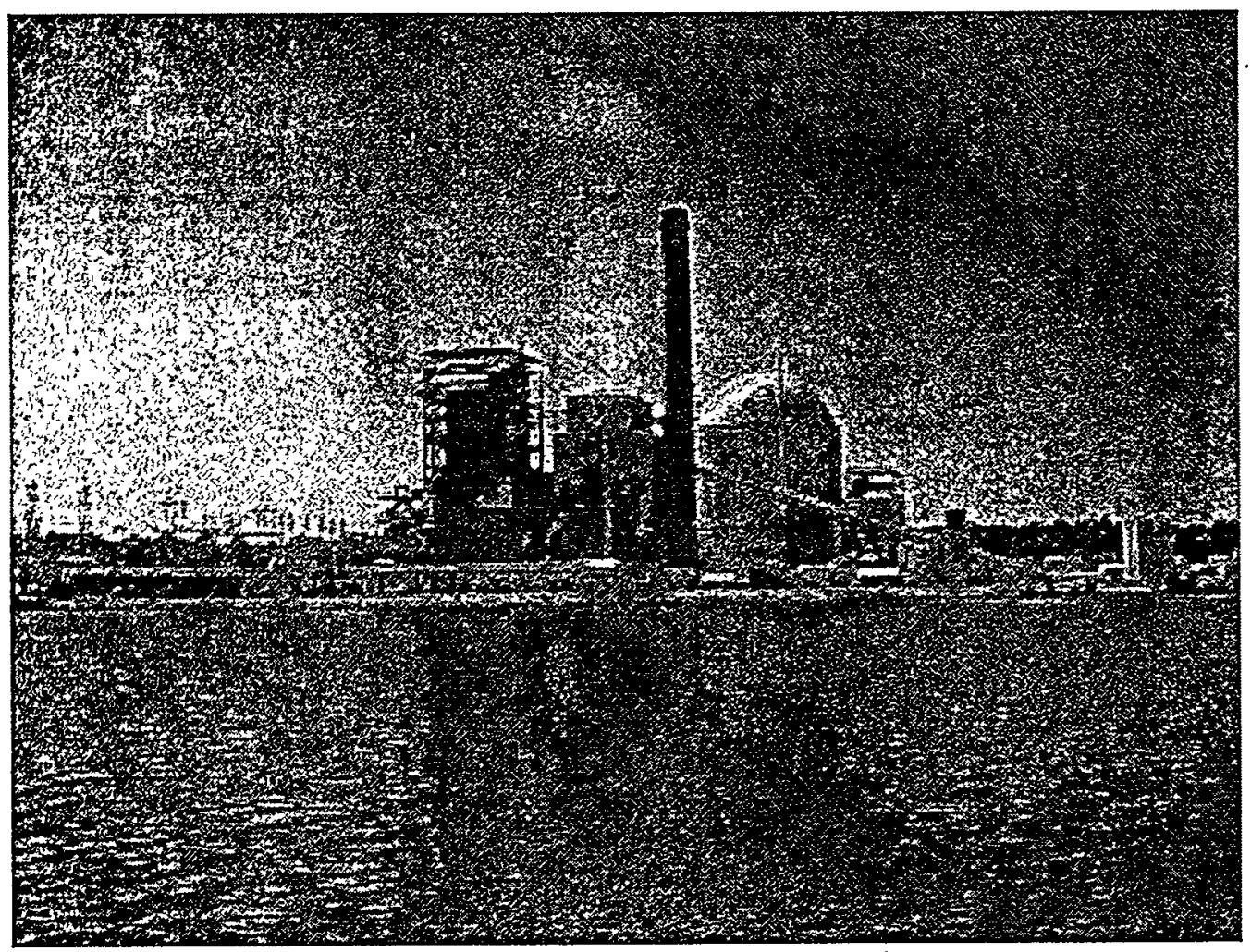

Figure 4: H. B.Robinson nuclear and fossil units viewed from lower end of cooling lake. The cooling lake is shallow and turbid due to natural tannins.in the water, which along with the waste heat from the power plant produce water temperatures above $40^{\circ} \mathrm{C}$ near the cooling water discharge in the summer.

NASA's Stennis Space Center (SSC) also plans to make skin and subsurface water temperature measurements in their HPIW reservoir, along with meteorological measurements and thermal images from a thermal camera mounted on a boom over the reservoir. For land temperatures, SRTC will use surfaces such as those at the NASA SSC V\&V target array, which are large and uniform and characterized spectrally (Figure 5). The brown stains on the target array were caused by water seepage. The target array is to be waterproofed and repainted prior to MTI launch. 


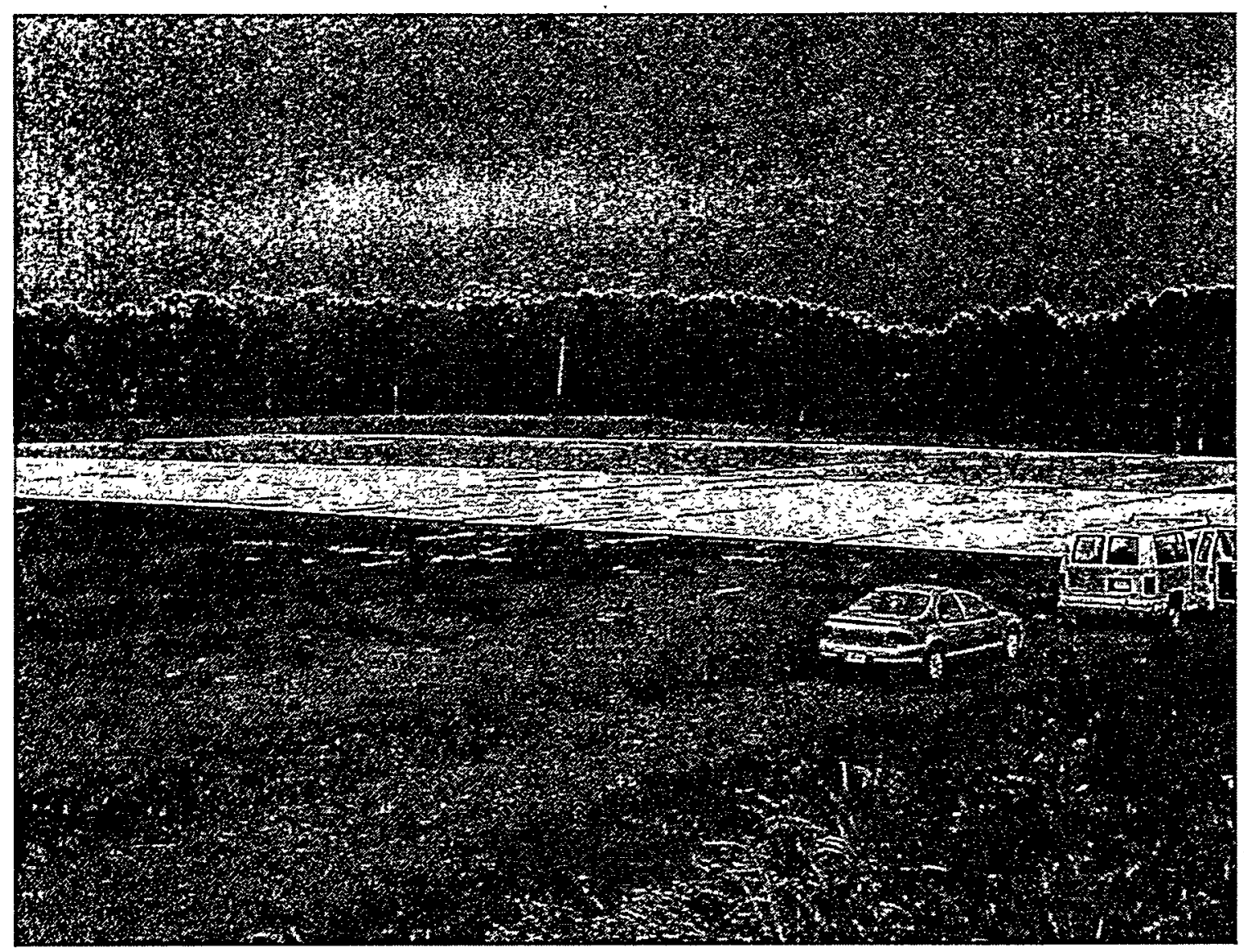

Figure 5: Part of the NASA Stennis Validation and Verification (V\&V) target array, showing dark, light and intermediate gray-scale targets.

\section{Robust Water Temperature Retrieval}

The MTI robust water temperature retrieval algorithm uses a statistical approach to determine water temperature. This approach models radiation transport for the five MTI thermal wavebands through a variety of atmospheres. For each channel and both look angles the Top-Of-Atmosphere (TOA) brightness temperature is computed as a function of surface water temperature. Linear regression is used to relate water surface temperature to TOA brightness temperature.

SRTC will use the same sites and methods used to validate the physics-based temperature retrieval algorithm to validate the robust water temperature retrieval algorithm. Our goal is to collect at least 30 usable images of the ground truth sites for robust and physics-based temperature retrieval to ensure that the results for temperature retrieval are statistically significant. The Tropical Western Pacific (TWP) ARM site on the island of Nauru in the western Pacific will provide excellent atmospheric characterization in a warm and extremely humid climate. Ocean surface temperatures will be measured at the end of a jetty that extends outward from the mouth of the Nauru harbor (Figure 6). Measurements from a fishing boat confirmed that ocean temperatures vary by only about $0.2^{\circ} \mathrm{C}$ in the area beyond the jetty. 


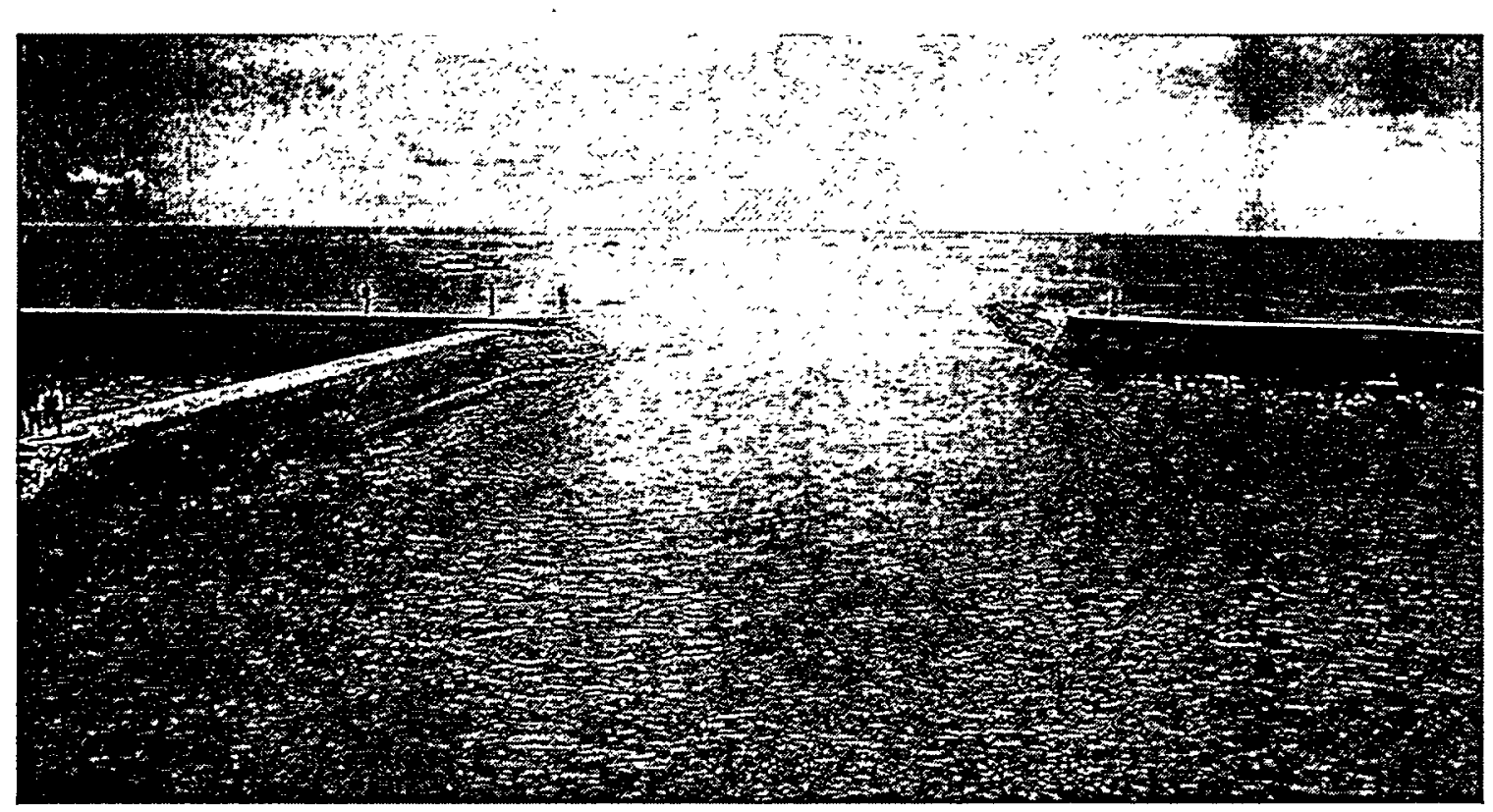

Figure 6: View of Pacific Ocean from Nauru harbor. Ocean temperatures will be measured from end of jetty on right side of harbor entrance.

\section{Detection of Boundaries of Bodies of Water}

This algorithm will compute expected reflectivity from a water surface and compare those values to observed reflectivity in a scene. It will make use of MTI bands A through D (visible and near infrared) and the low reflectivity of water to discriminate between land and water pixels. The algorithm will account for the somewhat higher reflectivity of turbid water and the effect of chlorophyll on band B (green). The expected reflectivity modeled by the algorithm will include the effects of wind speed, angle of incidence and angle of detection.

Many of the ground truth sites have bodies of water, including irregular ocean shorelines, Crater Lake (which contains Wizards Island), power plant cooling lakes, SRS lakes and the Turkey Point power plant cooling canals. These water bodies will constitute a diverse set of targets with different boundary configurations, temperatures and elevations for testing of the detection algorithm for water body boundaries. The Turkey Point power plant cooling canals present a complex water boundary detection problem. Figure 7 is a colorcoded thermal map of the canals created from a simulation by the ALGE code. The canals are about $60 \mathrm{~m}$ wide and the canal system covers an area that is about $7 \mathrm{~km}$ long and $4 \mathrm{~km}$ wide. The canals are straight except for localized areas where the mouth of a canal has been narrowed to reduce flow and redirect it to other canals. The land separating the canals is mostly highly reflective limestone (Figure 8), which provides good visible waveband contrast with the water. The long straight canals should provide a good test target for the water boundary detection algorithm. 


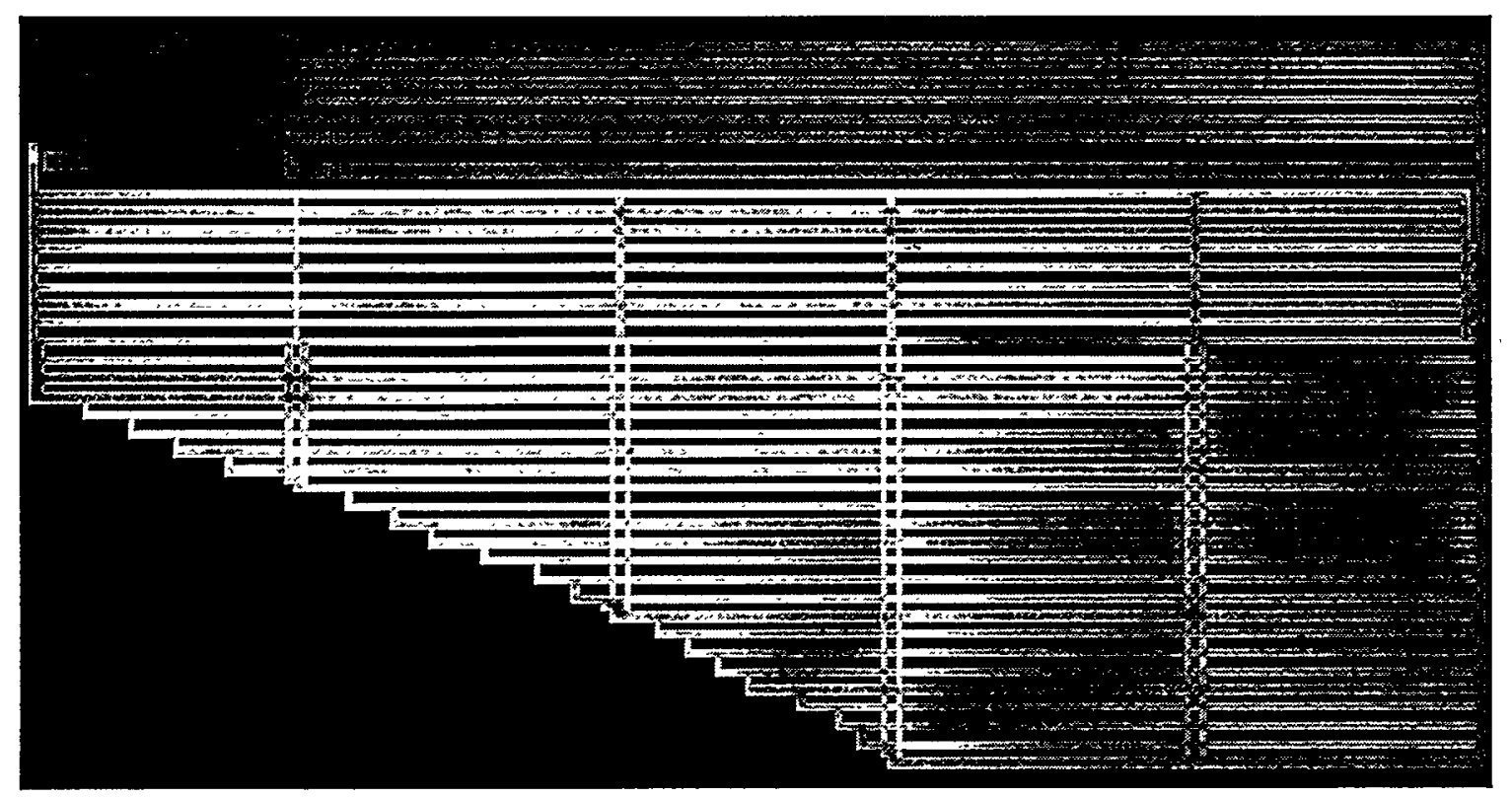

Figure 7: Color-coded thermal map of simulated Turkey Point power plant cooling canals. The canals are about $60 \mathrm{~m}$ wide and cover an area about $7 \mathrm{~km}$ by $4 \mathrm{~km}$.

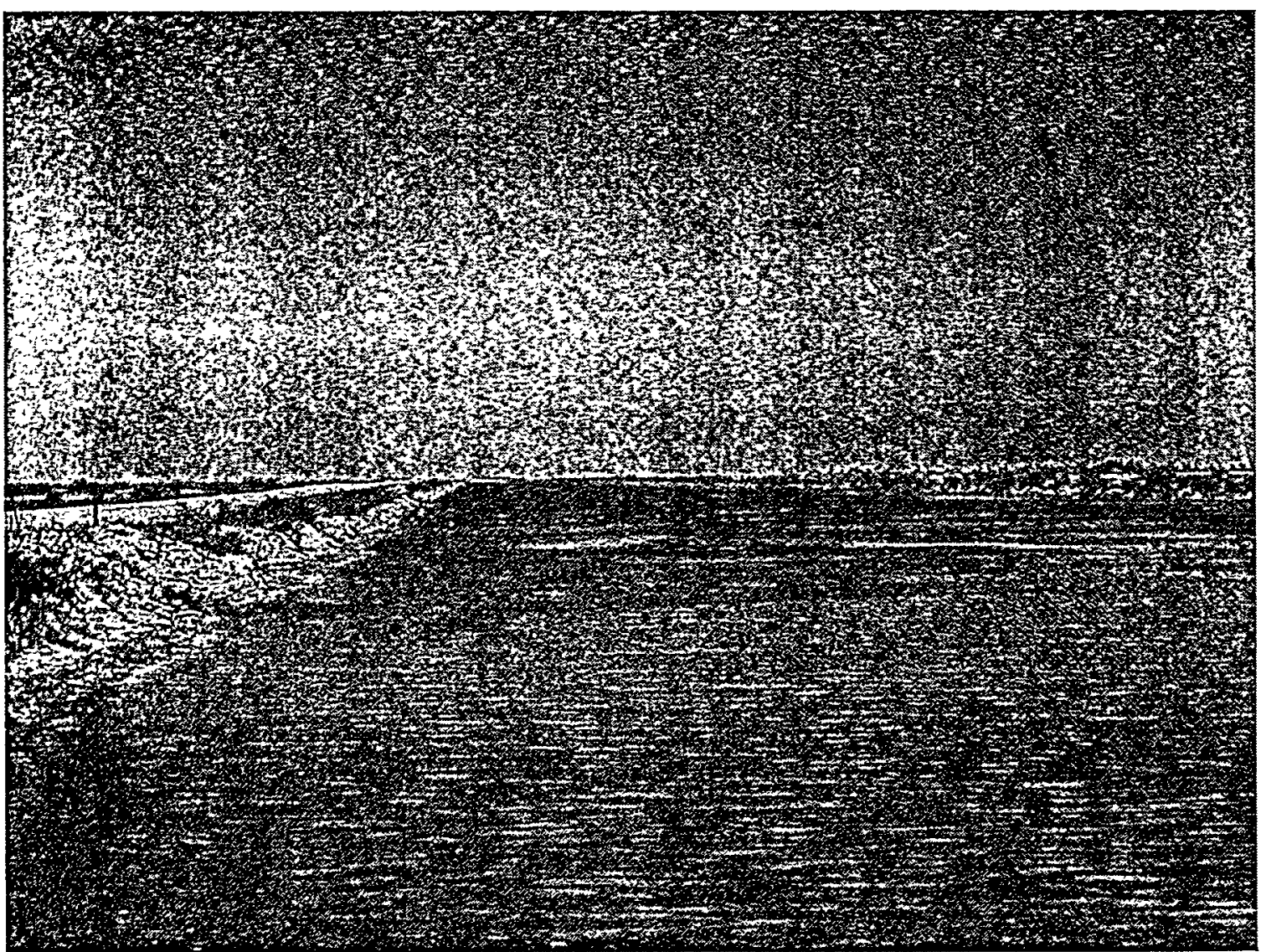

Figure 8: Photograph of Turkey Point power plant cooling canal. Distant object is reactor containment. 


\section{Subpixel Temperature Retrieval}

The subpixel temperature retrieval algorithm is directed primarily at recovering water temperatures from narrow channels or small bodies of water, which have manỳ mixed land-water pixels. The algorithm assumes that some pure (unmixed) pixels are available in the scene, which can be used to compute columnar water vapor and effective atmospheric temperature with the physics-based temperature retrieval algorithm. Radiance in the five MTI thermal wavebands, an emissivity estimate for the land surface, and an estimate of the fractional coverage of the pixel by land and water (derived from visible wavebands) are also needed. With these inputs, temperatures for the water and land parts of the pixel can be derived by finding a best fit to the measured radiances from the five MTI thermal wavebands.

Surface thermal discharges into power plant cooling lakes produce areas of water that are much warmer than adjacent land. These discharge locations are well suited to testing of this algorithm. Some power plants, such as the H. B. Robinson plant in South Carolina, use long, narrow discharge canals to carry heated water far from the cooling water intake (Figure 9). These long narrow canals are well suited to testing of the sub-pixel temperature retrieval algorithm, because there are many pixels with varying proportions of land and canal in a single image, but the canal and land temperatures are nearly constant along the entire length of the canal.

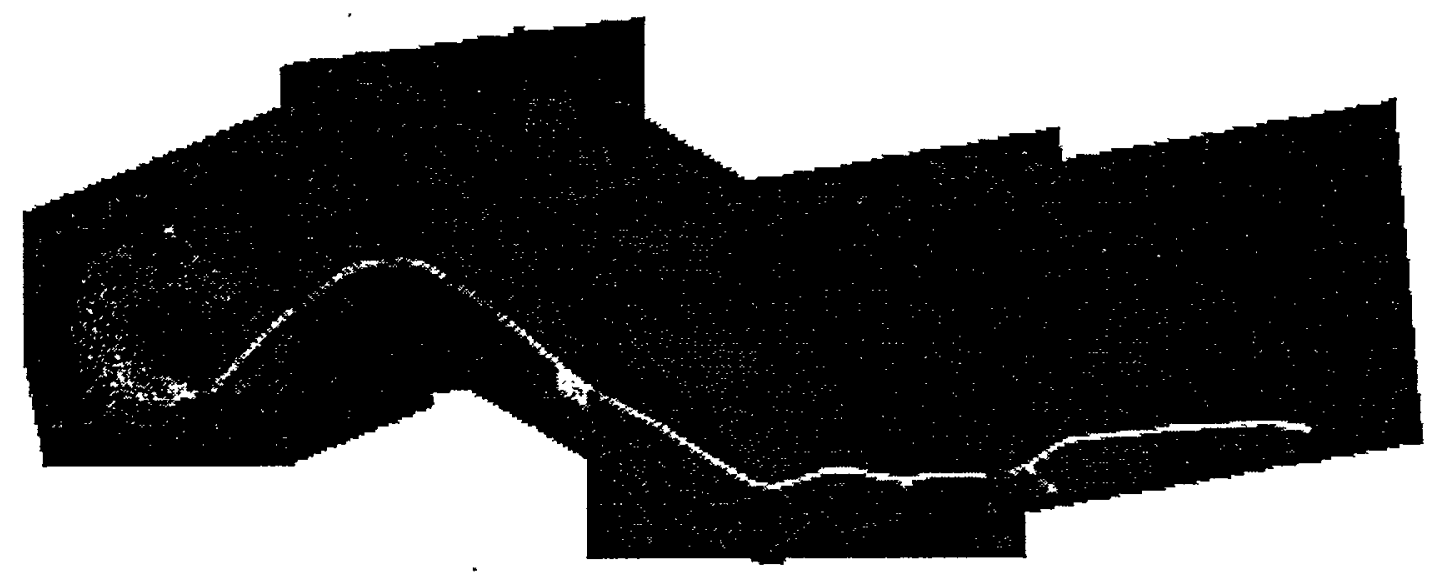

Figure 9: Color-coded mosaic of thermal images of the H. B. Robinson power plant's cooling lake. The discharge canal is about $8 \mathrm{~km}$ long and $20 \mathrm{~m}$ wide. The temperature drop from the cooling water discharge (lower right) to the point where the heated water enters the lake (lower left) is about $1.0^{\circ} \mathrm{C}$.

Other candidate subpixel temperature retrieval targets are rocket engine tests at NASA SSC and lava vents on the sides of Kilauea Volcano on the Big Island of Hawaii.

\section{Thermal Energy Discharge Rates Into Surface Water Systems}

This algorithm uses MTI imagery to determine the rate at which waste heat is discharged by an industrial facility to water bodies such as a cooling lakes, rivers and bays. Power plants and many other industrial facilities frequently use surface water systems to dissipate large quantities of waste heat. The temperature and amount of the water being discharged determine whether it has any adverse environmental effects. The thermal plumes created by the discharge of waste heat to the environment are well suited to analysis by thermal imaging. This algorithm combines calibrated thermal imagery from MTI, 3-D hydrodynamic modeling, local meteorological data and the physical characteristics of the surface water system to find the discharge rate (Garrett and Hayes ${ }^{7}$ ). Given the discharge rate, the amount of heat being injected into the environment can be found, and information about transport of other non-visible pollutants is generated. Figure 10 compares observed surface temperatures from Daedalus imagery of a SRS cooling lake to simulated temperatures for the same time generated by this algorithm. 

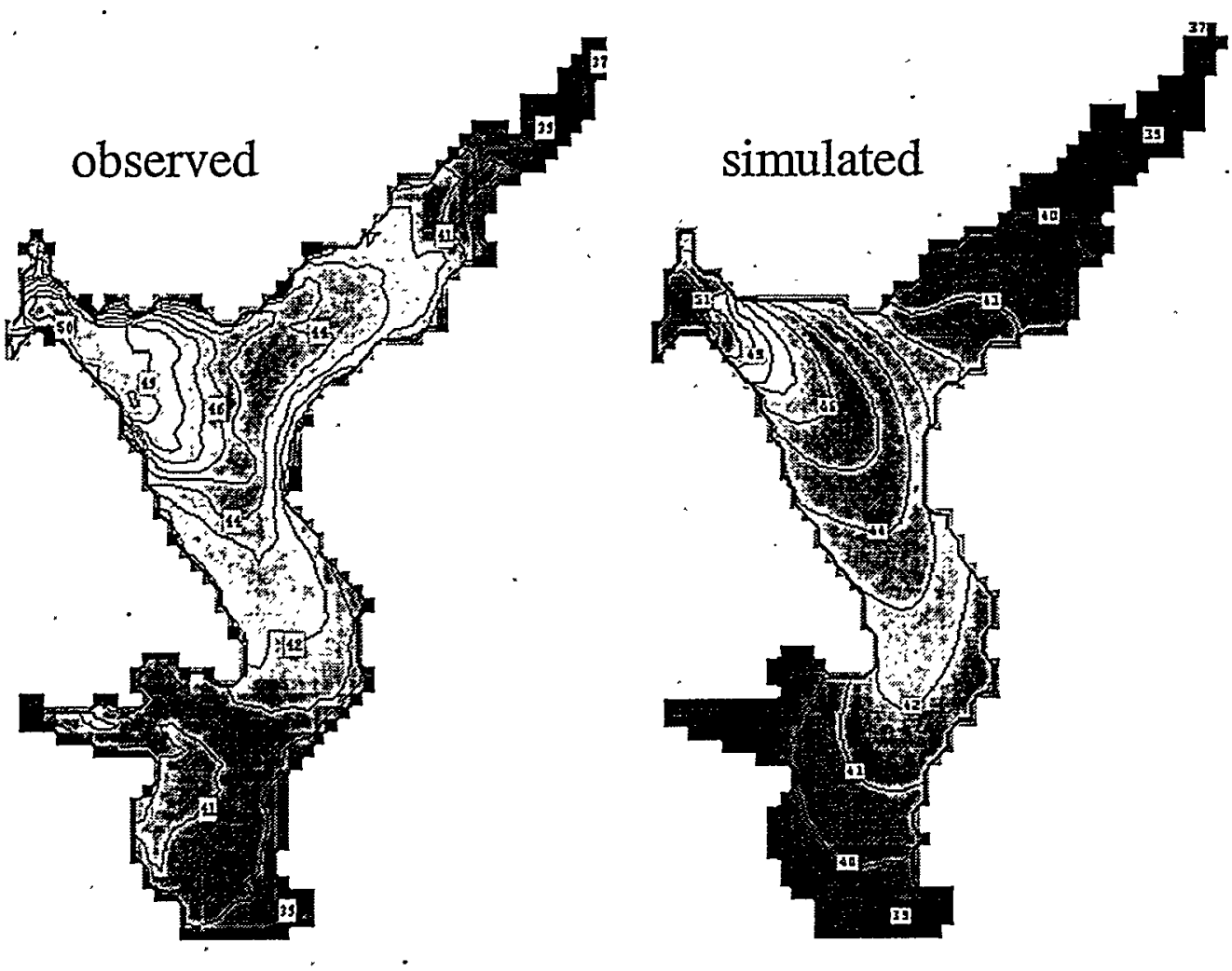

Figure 10: Observed and simulated Savannah River Site cooling lakes.

SRTC will validate this algorithm with data from four power plants in different parts of the country that use cooling lakes, cooling canals and ocean discharge to dissipate waste heat.

\section{Thermal Energy Discharge Rates Into the Atmosphere}

This algorithm uses MTI imagery to determine the rate at which waste heat is discharged to the atmosphere by an industrial facility. Power plants and other industrial facilities often use natural draft or forced draft cooling towers to dissipate waste heat in the atmosphere. Cooling towers can have several local impacts on the environment, including fog generation, icing, light snowfall and mist formation and cumulus cloud initiation. This algorithm will use calibrated thermal and visible MTI imagery, 3-D hydrodynamic modeling, local meteorological data and cooling tower specifications to estimate the rate at which water mass and enthalpy are being discharged to the atmosphere $\left(\mathrm{O}^{\prime} \operatorname{Steen}^{8}\right)$.

SRTC will collect ground truth data at the Vogtle power plant in Georgia to validate this algorithm. The Vogtle plant uses natural draft cooling towers. Ground truth data will include simultaneous visible and thermal images of the cooling tower plumes, ambient meteorology and internal cooling tower temperatures and flow rates. The visible imagery will be used to compute the volume of the cooling tower plumes at the time images are taken by MTI. The thermal imagery will be compared to MTI imagery and with radiative transfer calculations based on plume simulations. Figure 11 shows a series of photographs and simulated Vogtle plumes under calm meteorological conditions. 


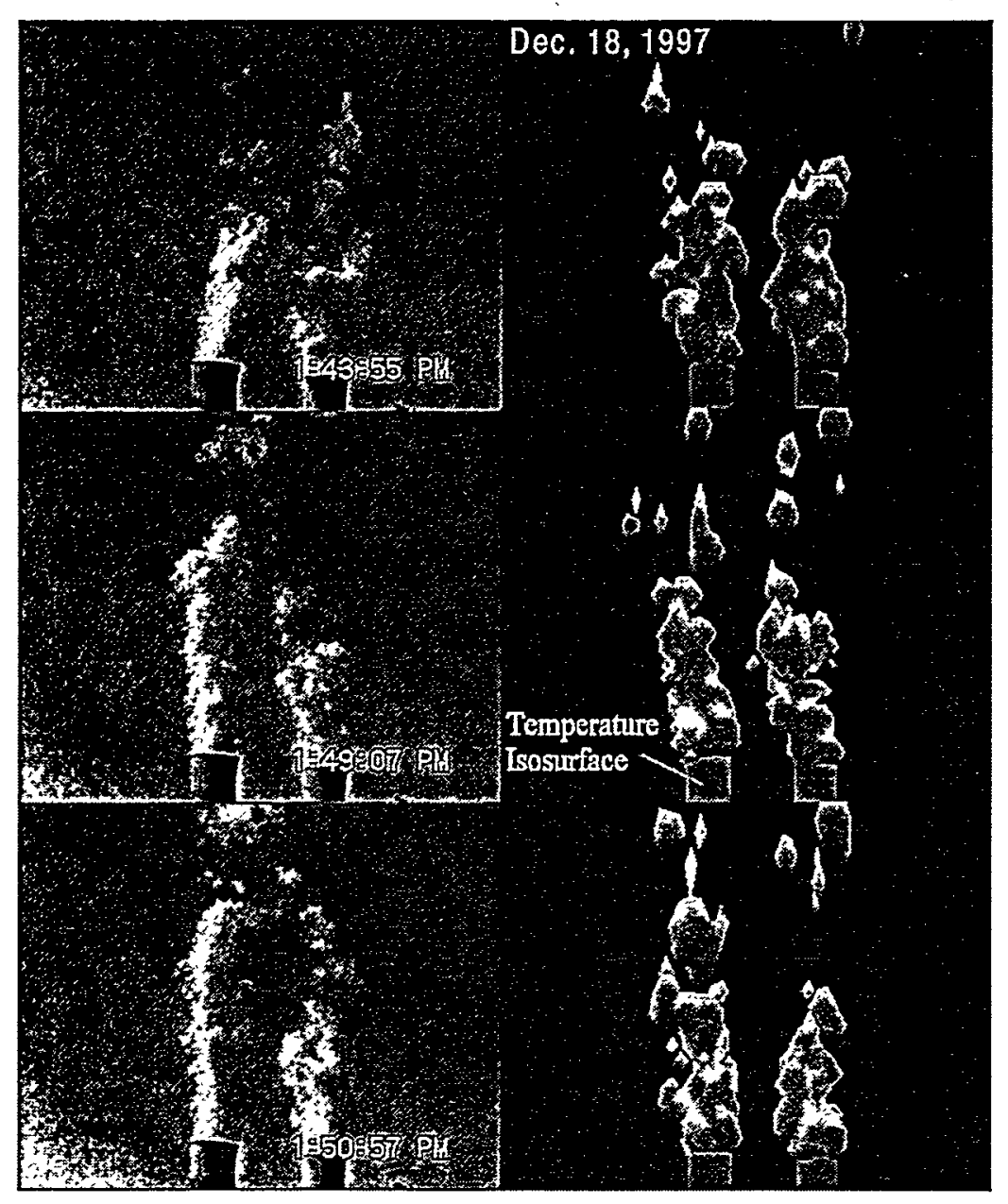

Figure 11: Camcorder images and simulated cloud water plumes for Vogtle plumes. The cloud water isosurface is at 0.01 $\mathrm{gm} / \mathrm{kg}$. The tower is visualized with a temperature isosurface at the tower exit air temperature.

\section{Cloud Masks}

This algorithm will attempt to identify and flag clouds in MTI images by combining threshold BRDF values across the visible and near infrared part of the spectrum with low brightness temperatures in the thermal part of the spectrum. It will attempt to discriminate between low clouds and surface objects through use of the nadir and $60^{\circ}$ images that MTI will take on a single pass over a target. The algorithm will also determine the areas shadowed by clouds because those areas will have only the diffuse component of reflected radiation.

Ground truth sites with large uniform surfaces such as water will provide the simplest tests of this algorithm. An excellent target is Lake Pontchartrain because it has uniformly turbid water and often has small cumulus clouds over it. Any of the other sites could be used as more challenging test locations, with the Crater Lake area offering the opportunity to discriminate between low clouds and snow. The Oklahoma ARM site will be attractive because its atmospheric characterization includes whole-sky cloud measurements. 


\section{Thin Cirrus Detection/Removal}

This algorithm uses MTI band $\mathrm{H}(1.36-139 \mu)$ to detect the presence of thin (sub-visible) cirrus clouds, which reflect solar radiation in this waveband that would otherwise be absorbed by water vapor in the lower depths of the atmosphere. It also uses band $\mathrm{H}$ to correct for the effect of thin cirrus clouds on the visible and near infrared channels (A through F). Since this algorithm can only be used during the day, some effort will be made to develop an algorithm that detects and removes the effects of thin cirrus at night. This appears to be possible, given MTI's well-calibrated thermal radiometry.

The ARM site in northern Oklahoma will provide the comprehensive atmospheric measurements needed to validate this algorithm. The central facility has a micro-pulse lidar, which is sensitive enough to detect subvisual cirrus.

\section{Scattering and Absorption by Aerosols}

This algorithm corrects the MTI visible and near-infrared channels for aerosol path radiance to derive true ground reflectance. The algorithm will use dark targets in the scene, such as thick stands of trees, to determine surface reflectance in the SWIR channel $O$ where atmospheric scattering and absorption are very weak. Reflectance values in MTI channels $A$ and $C$ are highly correlated with channel $O$ reflectance for dark targets. Aerosol optical depths in channels $A$ and $C$ can be calculated from the measured TOA radiances and the calculated surface reflectances. Remaining channel aerosol optical depths can be determined empirically through use of curve fits through channel.A and $C$ data. Given the aerosol optical depths for all channels, surface reflectances for the non-dark target scene pixels can then be calculated.

Crops such as sorghum and soybeans are grown on the farms surrounding the Southern Great Plains (SGP) ARM site in north central Oklahoma. The reflectances of these crops during growing season when they are dark green will be collected. These spectra, plus the comprehensive atmospheric characterization at the ARM sites (including aerosol measurements) will provide a ground truth database for validation of the algorithm. Figure 12 is a photo of the SGP ARM site showing the gently rolling, primarily agricultural landscape.

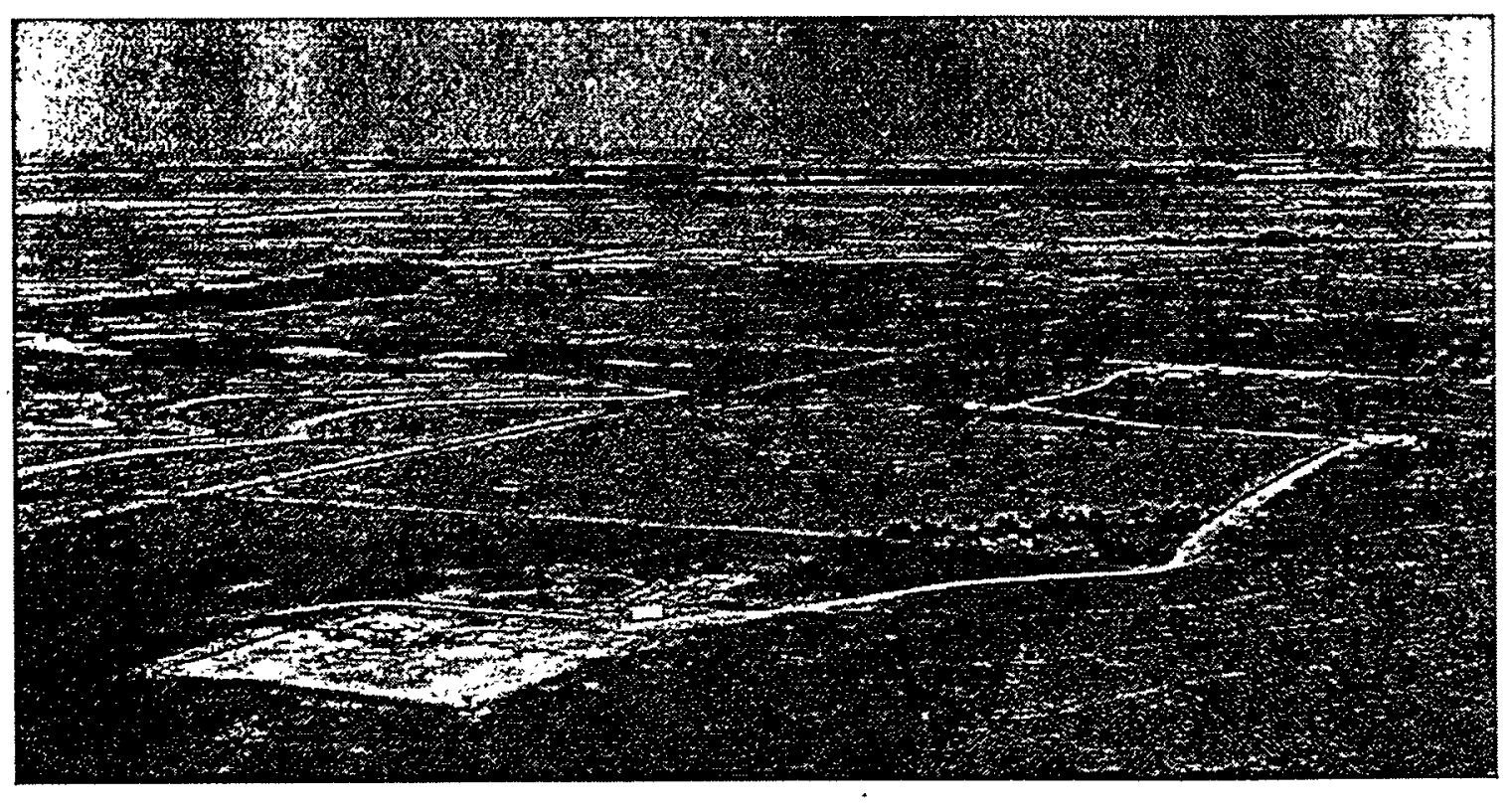

Figure 12: Southern Great Plains (SGP) Atmospheric Radiation Measurements (ARM) site in north central Oklahoma. Several MTI algorithms will be tested by combining the excellent atmospheric characterization at this site with crop reflectance spectra taken by ground-based instruments and by MTI. 


\section{Columnar Water Vapor Retrieval}

This algorithm will derive the atmospheric columnar water vapor content using reflected sunlight and the 0.94 micron water vapor absorption band (MTI Band F). A new technique called Atmospheric. Pre-corrected Differential Absorption (APDA) has been developed, which based on preliminary tests, appears to be more accurate than traditional Continuum Interpolated Band Ratio (CIBR) methods over many surface types. APDA improves on the empirical CIBR method by adding physics based on radiative transfer. .

Validation of the algorithm will require atmospheric profiles of humidity and temperature as a function of pressure. It will also require simultaneous ground-based sun photometer measurements of optical depth, uniform ground coverage with a $10 \mathrm{~nm}$ sampling reflectance spectrum, and cross-calibration of MTI channels $\mathrm{E}, \mathrm{F}$ and $\mathrm{G}$ with an airborne imaging spectrometer such as AVIRIS. We hope to have some simultaneous AVIRIS collections over the desert playas and the NASA-Stennis V\&V target array in Mississippi. The Oklahoma ARM site is another verification site, since it will have the atmospheric, sun photometer and other radiometric data.

\section{Vegetation Health}

The goal of this algorithm is to identify vegetation that has been stressed by atmospheric, surface or subsurface releases of pollutants from industrial sites. Since there are many natural sources of stress for vegetation, e.g., Iack of water, discrimination between anthropogenic and natural sources of stress will require time series of images and/or collateral information about the industrial site. The algorithm makes use of the fundamental observation that the chlorophyll content of vegetation under stress decreases, and along with it the relative peak in reflectance of green light (MTI Channel B). The algorithm will also use Channel I $(1.55$ to $1.75 \mu)$ to attempt to discriminate between stress caused by lack of water and other types of stress (Hunt et al. ${ }^{9}$ ). The algorithm will use a neural network to classify leaf reflectance data that has been binned and averaged over six MTI channels.

Vegetation stress has been studied at the Savannah River Site (SRS) for many years as a part of the environmental restoration program for areas affected by chemical and radioactive contaminants as a result of Cold War nuclear materials production (Blohm et al. ${ }^{2}$ ). Forested areas near SRS's D-Area have been affected by acidic runoff from coal ash and have already been the subject of research. Figure 13 shows the parts of Savannah River Site's D-Area where coal for power generation is stored, along with the associated runoff containment and ash basins. Effects of acidic water seepage from these basins on nearby trees may be detectable by applying the vegetation stress algorithm to MTI imagery of D-Area. 


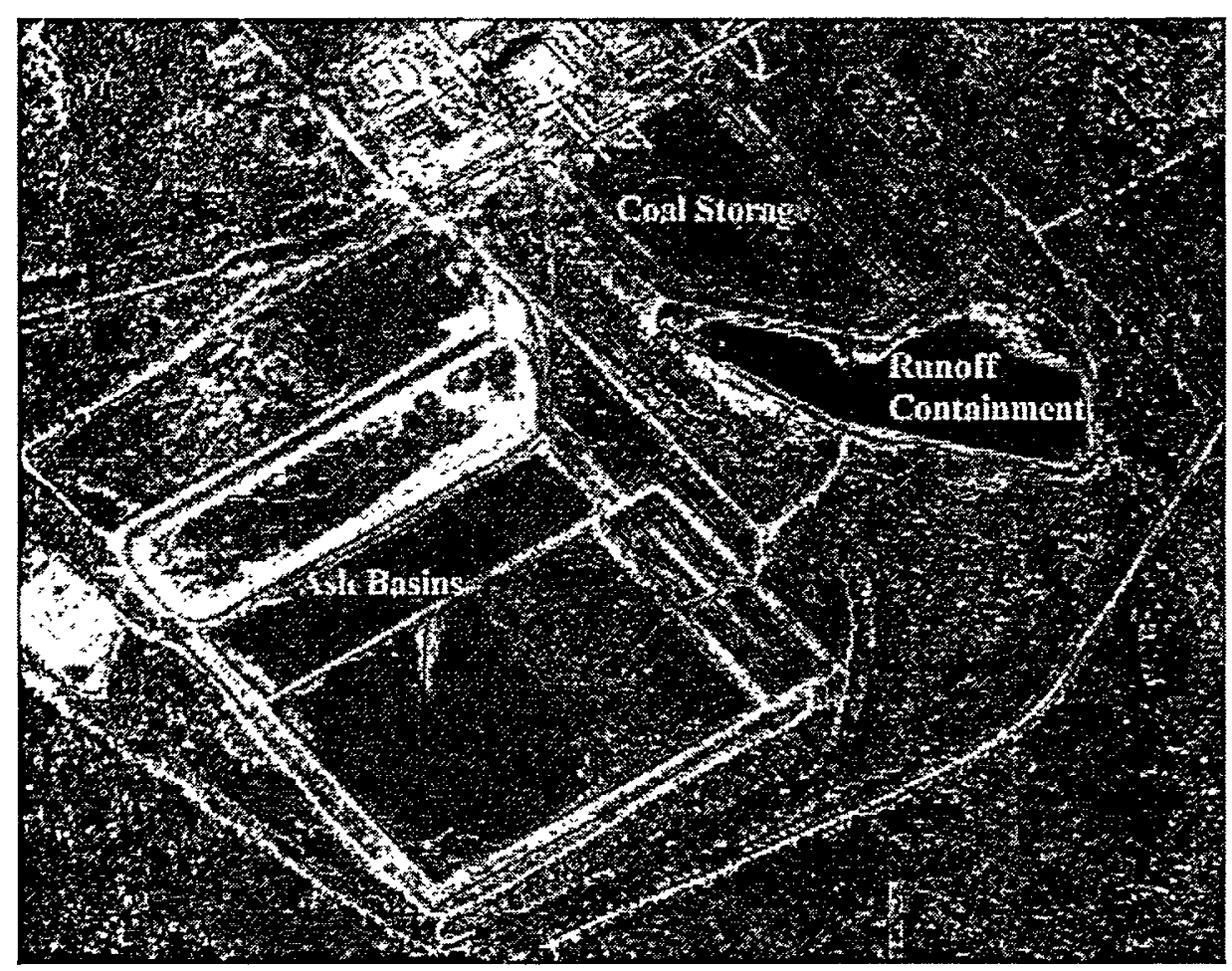

Figure 13: Savannah River Site's D-Area power plant uses coal to generate electricity. Vegetation stress may be detectable around the associated runoff containment basin and ash basins.

\section{Water Quality and Bathymetry}

Since there is an extensive literature on retrieval of water quality parameters from remote sensing data, we will apply existing methods and MTI channels A,B and C (blue, green, red) to retrieve water quality data. Primary quantities of interest are chlorophyll content, suspended sediments and yellow substance (dissolved organic matter). Codes such as $6 \mathrm{~S}$ will be used in the retrieval algorithm because they include relationships between water color and chlorophyll and the effects of wind on water reflectance.

The turbid lakes of the southeast U. S. typically have high chlorophyll contents due to high algal concentrations and even algal mats. Sites include power plant cooling lakes and unheated lakes at SRS, which are monitored as part of site environmental programs. Water quality is also a research focus at Crater Lake (Figure 14) which is an extremely clean body of water and which will provide data that sharply contrasts with imagery from the southeast U. S. lakes. 


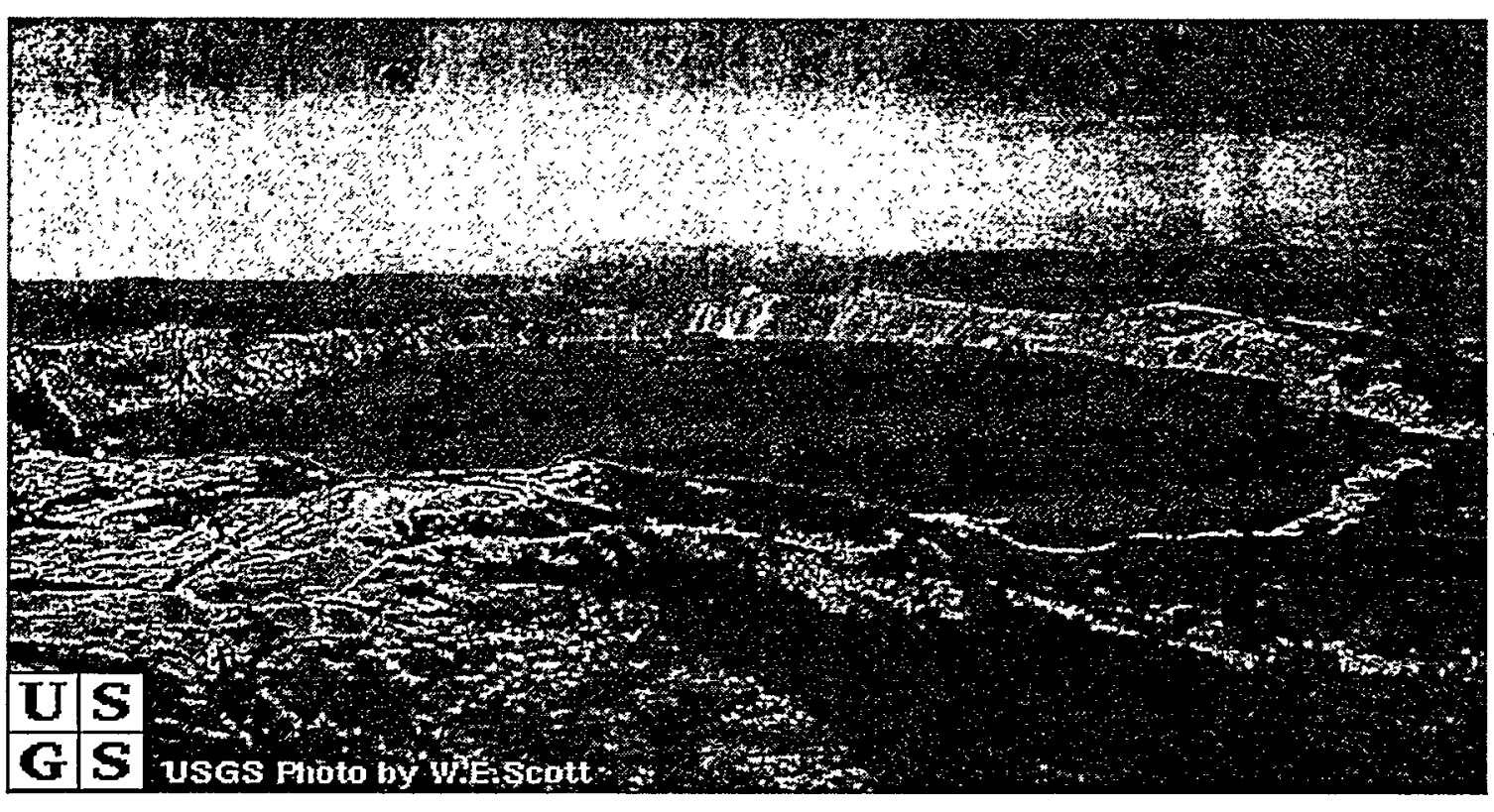

Figure 14: Crater Lake is an extremely clean, high altitude lake in southwest Oregon. MTI images of Crater Lake will be used to test water quality, bathymetry and temperature retrieval algorithms.

\section{Material Identification}

A k-means clustering algorithm will be used to distinguish between various types of materials within an MTI scene. This algorithm will use the three visible MTI channels (A, B, C), the near IR channel D and the shortwave $I R$ channels $I$ and $O$. The cluster centers will be determined from a library of spectral reflectance data for a wide variety of man-made and natural materials. The algorithm will assign each MTI pixel to one of the material categories.

The Savannah River Site (SRS) combines several large industrial facilities with large areas of natural forested terrain. There are asphalt, concrete and gravel roads, large metal waste tanks, coal piles, buildings with rooftops made of various materials and painted surfaces. Natural surfaces include forest, swamp, bare soil and waste sites that have clay caps with grass on top. Another target will be the uranium mining sites and associated tailings in New Mexico and Arizona. Figure 15 is a photograph of a large abandoned uranium pit mine in northeastern Arizona on Navajo lands. The pit is about $200 \mathrm{~m}$ long and about $100 \mathrm{~m}$ wide. Soil samples taken from the pit contain uranium ore and have reflectance spectra that are somewhat different from the surrounding undisturbed soil. 


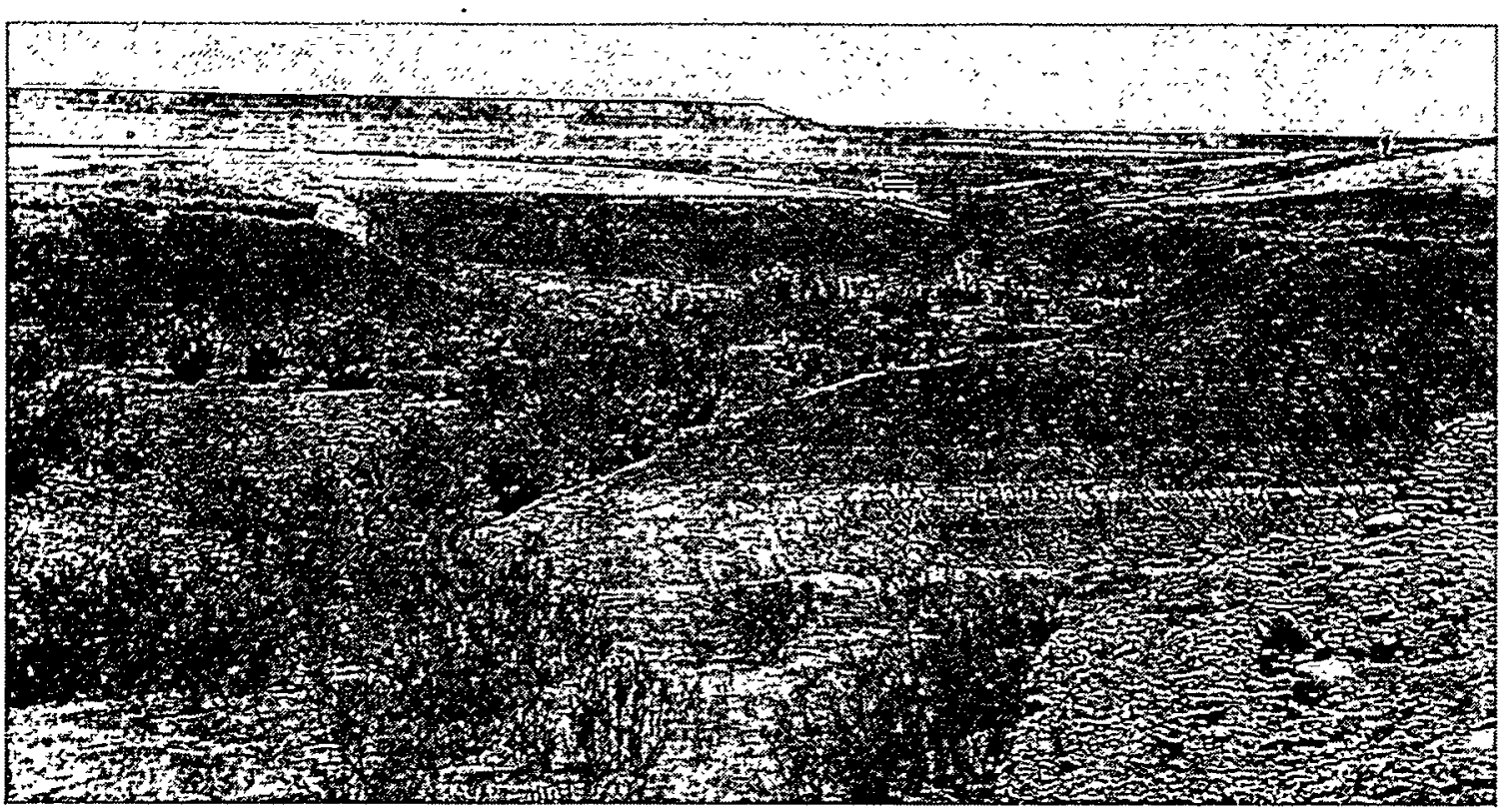

Figure 15: Abandoned uranium pit mine in northeastern Arizona.

\section{Ground Truth Measurements and Analyses}

A diverse set of radiometric and atmospheric sensors will be needed to collect ground truth data for MTI. At some sites it will not be possible to measure skin temperatures directly with a radiometer, so the skin temperature will have to be derived from bulk water and meteorological data. This section describes the instrumentation that SRTC will use to collect ground truth data, and the method that it will use to derive skin temperatures from bulk water data.

\subsection{Radiometric Measurements}

The intervening atmosphere between satellite and ground level surfaces affects the quality of the imagery recorded_by the satellite. The MTI satellite characterizes ground targets by measuring reflected and emitted radiance from 15 spectral bands in the range of 0.45 to 10.70 microns. The broad spectral range observed by the satellite encompasses the visible, NIR, SWIR, NWIR and LWIR. Present technology cannot satisfy all ground truth requirements needed by the satellite with a simple instrument. The broad spectral region has been subdivided in smaller regions based on availability of instrumentation, technical application, spatial and wavelength resolution.

MTI spectral bands A-D and $O$ are spectral bands primarily used for material identification. Bands E-F are used for the determination of atmospheric water vapor and band $\mathrm{H}$ for detection cirrus clouds. Band I will provide information related to vegetation stress through measurement of leaf water content. The retrieval of the temperature's surface is accomplished with the remaining 5 bands $(\mathrm{J}-\mathrm{N})$.

The FR spectroradiometer (Figure 16) and the Sun Photometer (Figure 17) manufactured by Analytical Spectral Devices (ASD) and the University of Arizona respectively, will be used to measure the visible and near infrared spectral regions. The primary function of the ASD FR spectroradiometer is to provide relative reflectance and absolute radiances of ground targets. The ASD FR spectroradiometer will be used in the 0.35 . to 2.5-micron spectral range encompassing bands A-I and band O. The Sun Photometer's primary purpose is to evaluate the skies' optical depth and therefore the aerosol concentration by measuring the solar radiation reaching the earth's surface. The Sun Photometer uses 10 spectral bands from 0.38 to 1.03 microns to calculate the sun's radiance. 


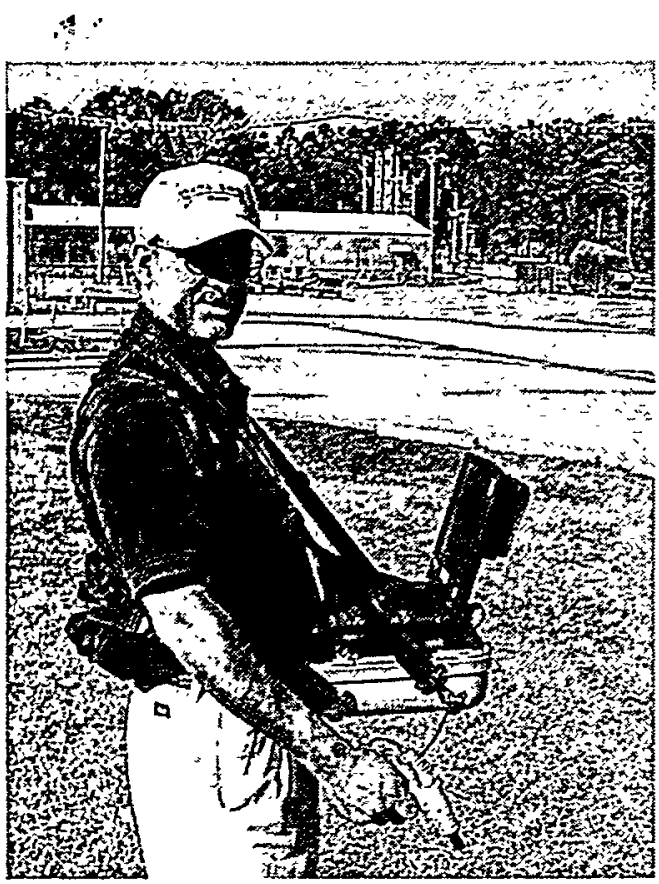

Figure 16: ASD FR spectroradiometer.

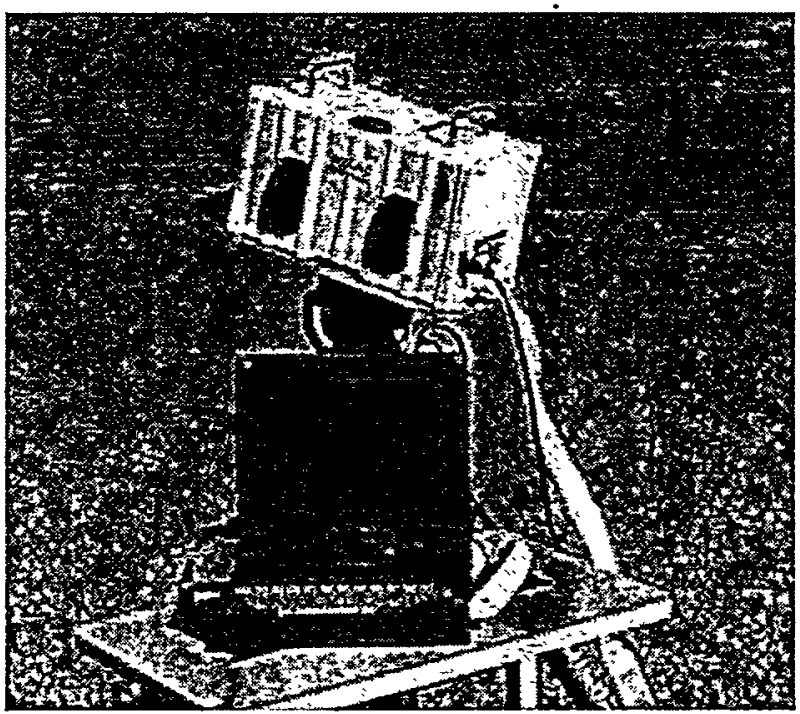

Figure 17: Fourier Transform Infrared Radiometer

The water and ground surface temperature is calculated from the radiance of the $5(\mathrm{~J}-\mathrm{N})$ bands in the MWIR and LWIR. Temperature measurements will be acquired with accurate glass thermometers traceable to NIST, hand-held digital thermometers, point radiometers, and imaging radiometers. Surface temperature measurements will be recorded using Heimann point radiometers manufactured by Heitronics (Figure 18). The radiometer's accuracy will be verified using blackbodies manufactured by MIKRON Corp. The temperature of extended surface areas will be measured using imaging radiometers manufactured by Inframetrics Corp. Two cameras from Inframetrics will be used to characterize the surface (model 760 and a portable SC2000). A Fourier transform infrared spectrometer manufactured by Midac Corp. will be used to measure the spectral radiance of the 5 bands used by the MTI satellite. 


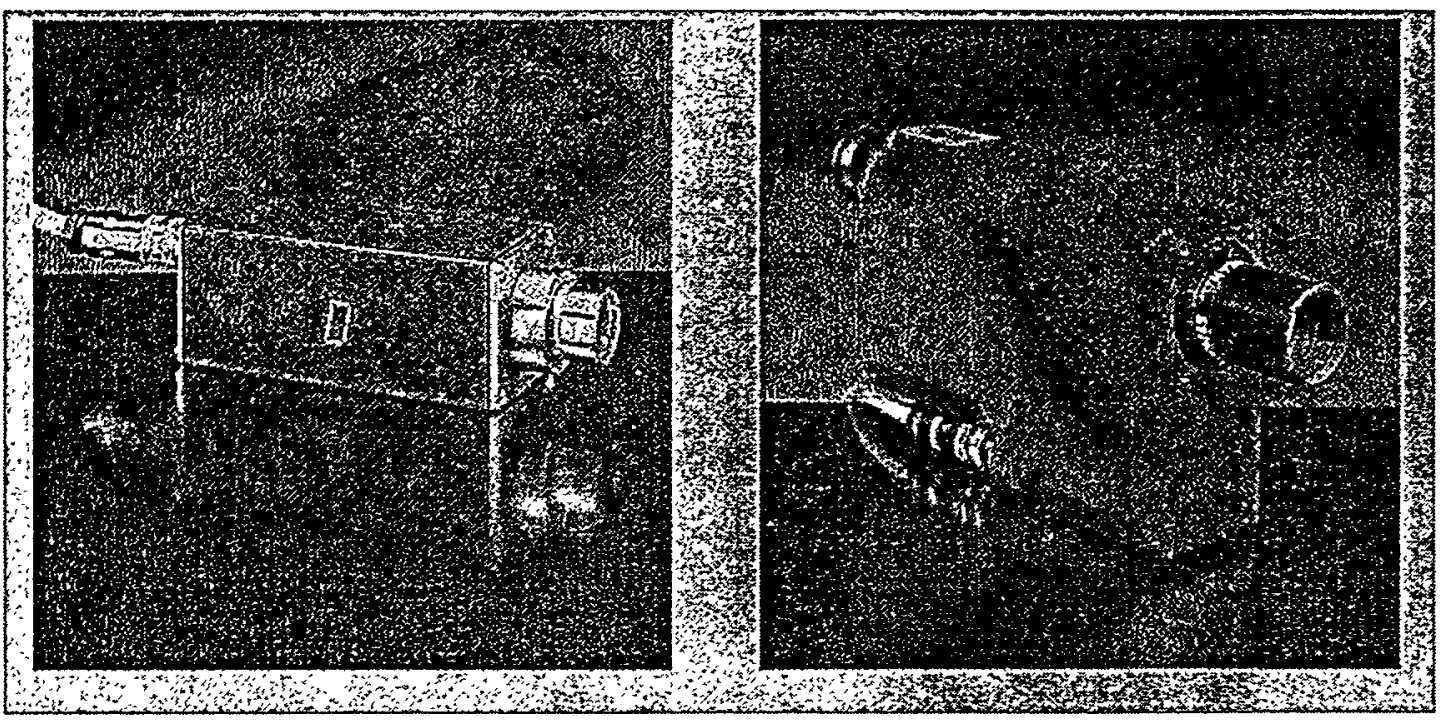

Figure 18: Heimann infrared radiation pyrometers.

\subsection{Skin Temperature Measurements}

In the past decade, the increased accuracy of satellite measurements has focussed attention on the difference between the temperature of bulk seawater (uppermost 10 centimeters of water) and the temperature of the 'skin' (the upper $1 \mathrm{~mm}$ ). This is because the skin temperature, which is measured by satellite, is typically 0.5 $-1.0^{\circ} \mathrm{C}$ less than the bulk temperature, the quantity usually measured from ship or buoy. The skin effect is more significant over bodies of fresh water because of the greater variability of water temperature, air temperature, wind and humidity. The skin temperature depression can be as large as $3^{\circ} \mathrm{C}$ over heated bodies of water, or even positive, as is the case of warm air over cold water. Understanding the skin temperature effect is of practical importance for ground truth programs because the bulk temperature is much easier to measure accurately than the skin temperature.

Although the skin temperature effect has been studied in the past (Schluessel et al. ${ }^{10}$ ), a reliable method to estimate its size and variability for a range of conditions is not available. The most important factors which govern the skin temperature effect are the exchange of $I R$ radiation between the water surface and the atmosphere, heat transfer from the surface to the atmosphere via latent and sensible heat flux, and mixing of the sea surface. Typically, the skin temperature depression is increased by radiative loss and evaporation and decreased by turbulent transport of heat upward through the bulk water layer.

To study the skin temperature effect, an experimental apparatus (Figure 19) has been constructed, which can be anchored in bodies of water, and which measures the air temperature, humidity and wind speed, the broadband $\mathbb{R}$ and visible heat exchange, the water temperature and the skin temperature. The skin temperature is measured with an $8-14$ micron radiometer, which is positioned approximately 0.5 meters above the water. 


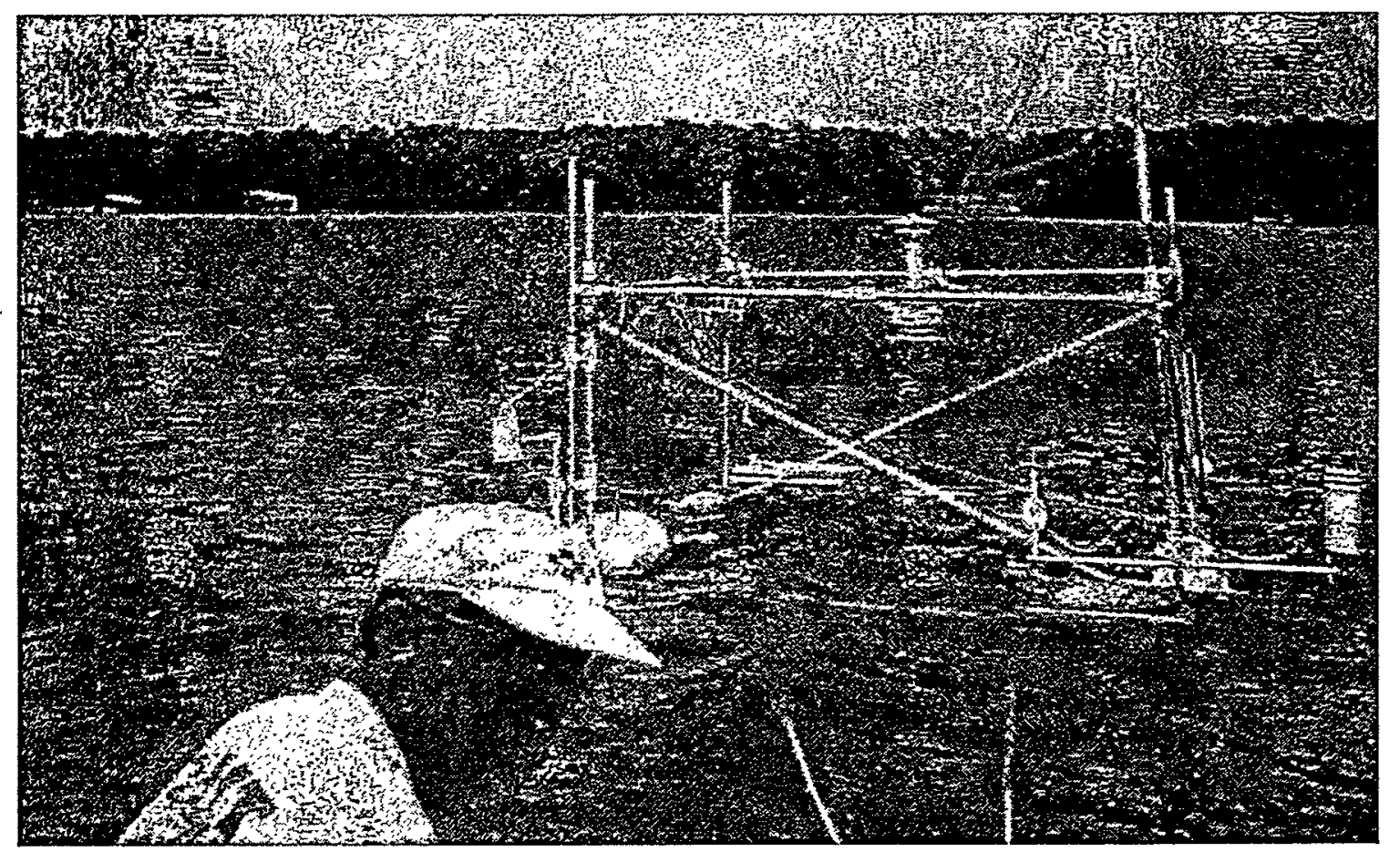

Figure 19: Skin temperature measurement apparatus being towed into H. B. Robinson cooling lake as Dr. Robert J. Kurzeja, developer of the skin temperature apparatus, looks for a mooring location.

The skin depression is determined by comparing the temperature measured with the radiometer (skin temperature) and a thermocouple at $10 \mathrm{~cm}$ below the surface (bulk temperature). Because of the inherent difficulties of this approach, the skin temperature depression was also determined by comparing radiometer measurements of the natural water surface and the 'stirred' surface. The 'stirred' surface temperature was obtained by pumping a jet of water from $10 \mathrm{~cm}$ below the surface into the radiometer's field of view. Because the skin depression takes $\sim 10 \mathrm{sec}$ to form, the stirred temperature will be equivalent to the bulk temperature.

Figure 20 shows results obtained from an unheated SRS lake on March 18 and 19 of 1999 . The figure shows the bulk water temperature at $10 \mathrm{~cm}$ deep (thermocouple), the radiometer temperature of the natural water surface, and the radiometer temperature of the pumped water (the vertical bars at 10 minute intervals). The pump was operated every 10 minutes for 10 seconds. The radiometer "pump temperature" is the average of the radiometer measurements at 4, 6,8 and 10 seconds after the pump was turned on. Ideally, the bulk water temperature will equal the temperature of the pumped water as measured by the radiometer. Figure 20 shows, however, that the radiometer pumped water temperature is $\sim 0.2 \mathrm{C}$ cooler than the bulk temperature. This is due to a bias of the radiometer of $-0.05 \mathrm{C}$ compared to the thermocouple and to the contribution to the radiometer temperature from reflected (cooler) sky radiation. This effect is estimated to about $-0.2 \mathrm{C}$.

An interesting feature in Figure 20 is the greater variability of the temperature of the natural water surface compared with the pumped water temperature; both obtained with the radiometer. This difference is surprising since the former is an average of 30 values while the latter is an average of 4 values. However, this difference is believed to reflect the large variability of the skin temperature in very light winds (less than $1 \mathrm{~m} / \mathrm{s}$ ), when large skin temperature depressions can form because in the absence of mixing in the bulk water layer. The results also suggest that the skin temperature effect may be most difficult to account for over small inland bodies of water on clear nights, when the winds will be near calm. Conversely, the most reliable estimates of the skin temperature may be possible during windy days, when the water surface and atmospheric boundary layer are well mixed. 


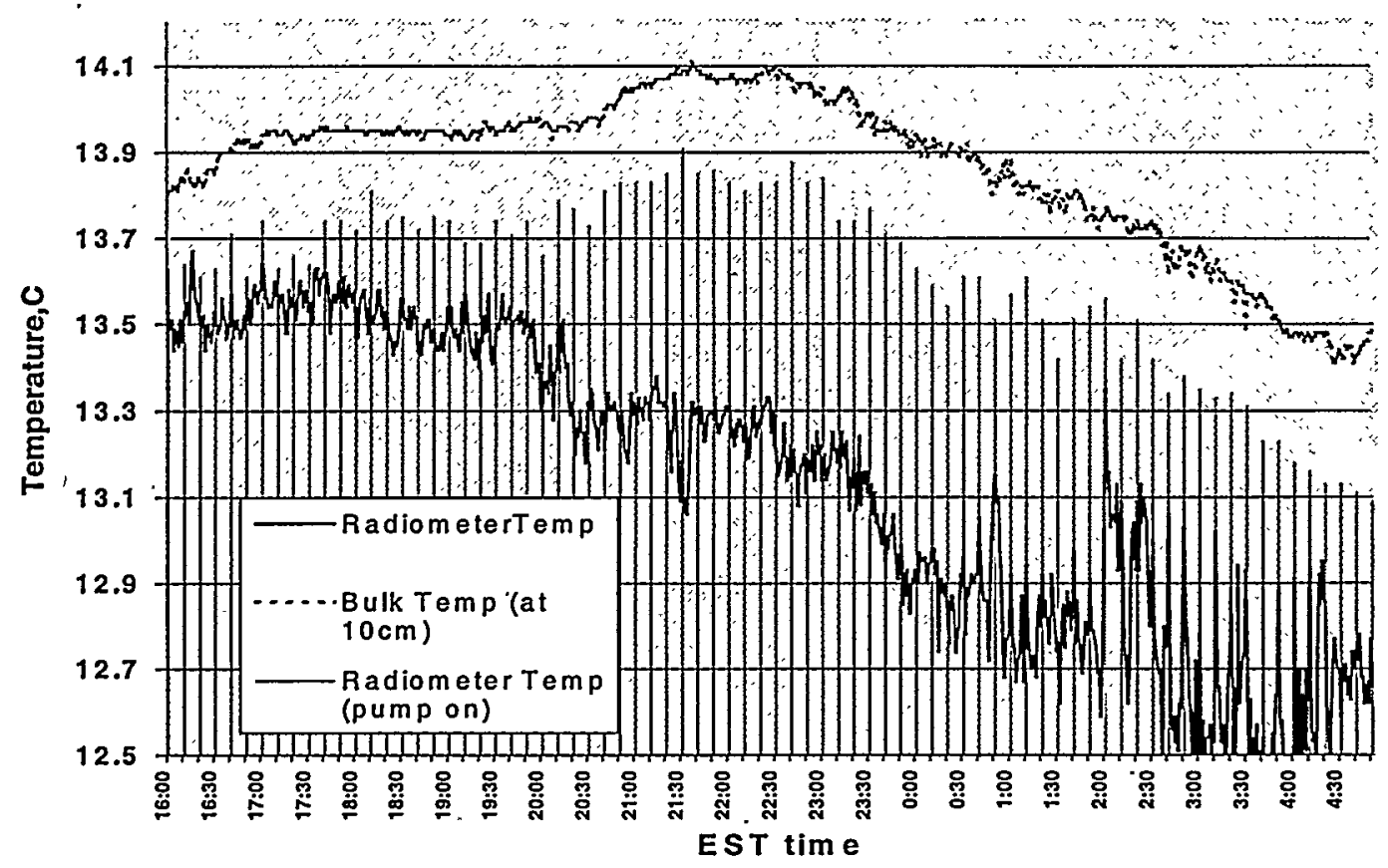

Figure 20: Comparison of measured skin and bulk water temperatures in SRS cooling lake.

\subsection{Skin Temperature Modeling}

At most MTI ground truth sites it will not be possible to measure the skin temperature directly. Instead, bulk water temperature measurements from just below the surface will have to be corrected for the skin temperature effect. Using data collected by the experimental apparatus shown in Figure 19, SRTC has developed a mathematical model that computes the skin temperature as a function of local meteorological conditions and the bulk water temperature just below the surface. The basic assumption of this model is that the skin temperature is the temperature at which the energy being lost to the atmosphere by evaporation, convection and radiation is balanced by the energy supplied from the bulk water layer below by turbulent mixing. SRTC has taken data at SRS's L-Lake and the H. B. Robinson cooling lake and compared model predictions to the observed skin temperature depressions. Figure 21 compares data taken at the H. B.

Robinson cooling lake near the cooling water discharge where the bulk water temperature was about $33^{\circ} \mathrm{C}$. The computed skin temperature depressions track the observed values fairly well and the average over the entire period of observation is very close. However, for a few of the individual one-minute averages, there are differences between observed and computed skin temperature depressions of about $0.5^{\circ} \mathrm{C}$. The skill of the model varies with weather conditions. The most difficult conditions appear to be nighttime with light winds. Apparently under these conditions turbulent mixing is weak and intermittent with large spatial and temporal . variability. Since the skin temperature apparatus takes point skin and bulk water temperature measurements that are separated by a few meters, small-scale spatial variability in skin temperature depression would increase model prediction errors. We expect that over an area as large as an MTI pixel that the small-scale variability would average out, but this has not yet been demonstrated yet. Results with the model to date indicate that the skin temperature correction will have an RMS error of about $0.3^{\circ} \mathrm{C}$. We hope to reduce that error with additional measurements that include thermal images and with model improvements. 


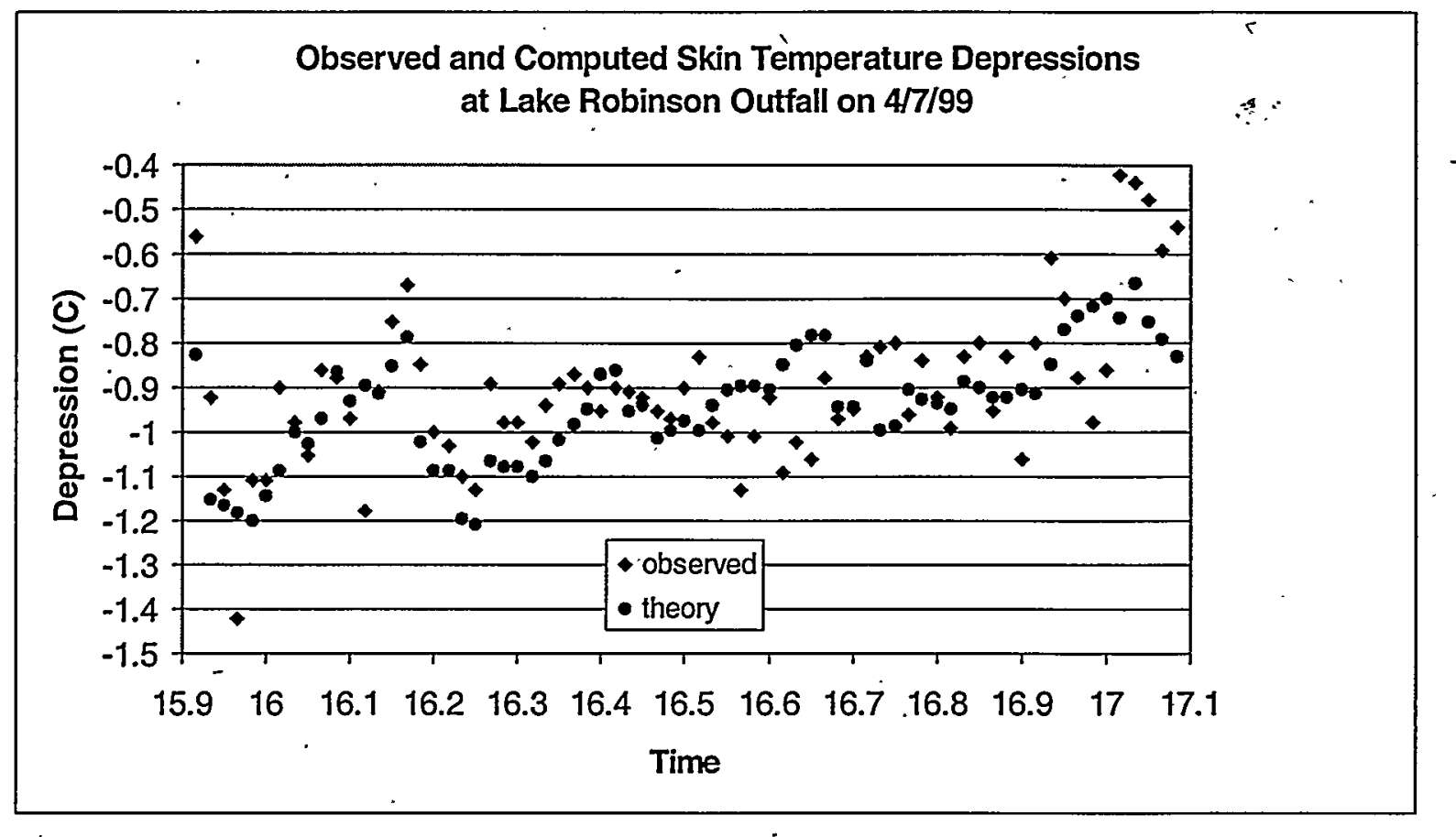

Figure 21: Observed and computed skin temperature depressions at Lake Robinson outfall on 4/7/99.

\subsection{Atmospheric Characterization in Support of MTI Ground Truth Collection}

MTI temperature retrieval algorithms have been developed to eliminate interference from atmospheric constituents such as water vapor, aerosols, ozone and air pollution. Of the four constituents listed, only column-integrated water vapor will be derived from the image data and output as a water vapor image. The success of the MTI algorithms for accounting for atmospheric effects will be evaluated indirectly through comparisons of image derived water temperature and ground truth measurements. It is desirable to quantify the accuracy of the temperature retrieval as a function of meteorological conditions and to collect sufficient ground truth data to determine causes for temperature retrieval errors leading to subsequent algorithm improvement. This will be accomplished at two ARM sites operated by DOE: the Great Plains ARM Site in north-central Oklahoma, near Ponca City and the Tropical Western Pacific ARM Site about $1500 \mathrm{~km}$ east of New Guinea on the island of Nauru. These sites utilize state-of-the-art equipment to characterize the complete atmosphere using radiosondes, microwave radiometers, LIDARs, numerous radiometers, radar and all-sky cameras.

Two of the MTI algorithms ( 8 and 9) require estimates of boundary-layer meteorology such as wind speed, humidity, and air temperature, in addition to information derived from the image. Algorithm 8 estimates power dissipation from cooling lake thermal imagery, but requires the meteorological data to compute heat losses from the lake to the atmosphere. Algorithm 9 estimates power dissipation from visible and thermal imagery of cooling towers, but also requires meteorological data. A meteorological model, such as RAMS or ETA, will provide estimates of the boundary layer meteorology or, if available, interpolate from near-by weather observations. As above, model accuracy can be determined directly from ground truth data for a few sites and inferred for others. The cooling tower model will be evaluated at Plant Vogtle, GA and the cooling lake model will be evaluated at four nuclear power plants. Model accuracy will be dependent upon model inputs including boundary-layer meteorological data, and will be affected by the accuracy of the temperature retrieval described above. In order to assist in the evaluation process, atmospheric water vapor and 
temperature profiles will be measured with the balloon-borne Atmospheric Meteorological Research System (AMRS) and atmospheric aerosols will be measured with a 6-channel spectral photometer. These measurements are not as complete as those made to characterize the atmosphere at the ARM sites but will provide a means by which model errors'can be separated from those affecting temperature retrieval.

Measurements of surface water temperatures are critical for ground-truth corroboration against MTI satellite imagery. Typical monitoring locations include areas where large temperature gradients are present such as power plant cooling lakes. Measurements must be made within the upper $10 \mathrm{~cm}$ of the water body to ensure a proper representation of the surface water temperature. Where necessary, buoys or other similar floatation devices will be used to maintain the proper monitoring level. Probe types include precision thermocouple or platinum resistance devices that are calibrated against traceable standards. Data will be collected locally and, in some cases, are made available remotely via telecommunication hardware in near-real time.

\section{SUMMARY}

We have used the 16 MTI science algorithms as our guide for selection of ground truth collection sites. These sites are in a variety of climatic regimes including humid subtropical (Southeast U. S.), hot dry desert (Southwest), cool, high altitude (Pacific Northwest) and cool maritime (Northeast). Collectively, these sites will provide data needed to validate all of the MTI algorithms. The data will be collected in collaborative relationships with other government agencies, universities and private organizations.

\section{ACKNOWLEDGMENTS}

The US Department of Energy supports this work at Sandia National Laboratories, Los Alamos National Laboratory and the Savannah River Technology Center. We appreciate the support of our colleagues at these laboratories and the support of the different private and public organizations working with us on MTI ground truth collections.

\section{REFERENCES}

1. D. S. Negri, J. E. Shines, "Thermal infrared surveys of the Savannah River Plant", DOE(ONS-SRL)8601, DOE Remote Sensing Laboratory, Las Vegas, Nevada, 1986.

2. J. D. Blohm, L. R. Tinney, and H. E. Mackey, Jr., "The integration of airborne multispectral scanner data and geographic information system technology for wetland remediation and vegetation stress detection studies at the Savannah River Site." Proceedings of ER '93, Environmental Remediation Conference, October 24-28, 1993, Augusta, Georgia, WSRC-MS-93-0385X, 1993.

3. P. J: Bresnahan, D. J. Cowen. J. R. Jensen, and H.E. Mackey, Jr., "Integrating heterogeneous data to develop a large-scale environmental data atlas for multi-platform users." Proceedings GIS/LIS '94 Annual Conference and Exposition, October 25-27, 1994. Phoenix, Arizona. pp. 96-104.,WSRC-MS94-0418, 1994.

4. B. W. Smith (editor), "Handbook of science algorithms for the Multispectral Thermal Imager", LA-UR 98-306, Los Alamos National Laboratory, Los Alamos, New Mexico, 1998.

5. W. B. Clodius, S. C. Bender ànd B. W. Smith: "MTI On-orbit Calibration", in: Imaging Spectrometry V, M. R. Descour and S. S. Shen, Editors, Denver, 18-23 July 1999, Proc. SPIE Vol. 3753, (1999).

6. P. N. Slater, S. F. Biggar, K. J. Thome, D. I. Gellman, P. R. Spyak, "Vicarious radiometric calibrations of EOS sensors", J. Atmos. And Oceanic Tech., 13, 349-359, 1996.

7. A. J. Garrett and D. W. Hayes, "Cooling lake simulations compared to thermal imagery and dye tracers", J. Hydr. Engrg., ASCE, 123, 885-894, 1997.

8. B.L. O'steen, "Plant Vogtle cooling tower studies", WSRC-TR-99-00174, Savannah River Technology Center, Aiken, SC, 29808, 1999.

9. E. R. Hunt, B. N. Rock, P. S. Nobel, "Measurement of leaf relative water content by infrared . reflectance", Remote Sens, Environ. 22, 429-435, 1987. 
10. P. Schluessel, W. J. Emery, H. Grassl, T. Mammen, "On bulk-skin temperature difference and its impact on satellite remote sensing of sea surface temperatures", J. Geophys. Res., 95, 13341-13356, 1990. 